\title{
Intrathecal delivery of recombinant AAV1 encoding hepatocyte growth factor improves motor functions and protects neuromuscular system in the nerve crush and SOD1-G93A transgenic mouse models
}

Sang Hwan Lee ${ }^{2}$, Subin Kim¹, Nayeon Lee ${ }^{1,2}$, Junghun Lee ${ }^{1}$, Seung Shin $\mathrm{Yu}^{1}$, Jin Hong Kim² and Sunyoung $\mathrm{Kim}^{1^{*}}$ (1)

\begin{abstract}
Amyotrophic lateral sclerosis (ALS) is a fatal neuromuscular disease resulting from motor neuron degeneration that causes muscle weakness, paralysis, and eventually respiratory failure. We investigated whether recombinant adenoassociated virus encoding human hepatocyte growth factor (rAAV-HGF) could generate beneficial effects in two mouse models with neuromuscular problems when intrathecally delivered to the subarachnoid space. We chose AAV serotype 1 ( $\mathrm{rAAV1}$ ) based on the expression levels and distribution of HGF protein in the lumbar spinal cord (LSC). After a single intrathecal (IT) injection of rAAV1-HGF, the protein level of HGF in the LSC peaked on day 14 and thereafter gradually decreased over the next 14 weeks. rAAV1-HGF was initially tested in the mouse nerve crush model. IT injection of rAAV1-HGF improved mouse hindlimb strength and rotarod performance, while histological analyses showed that the length of regenerated axons was increased and the structure of the neuromuscular junction (NMJ) was restored. rAAV1-HGF was also evaluated in the SOD1-G93A transgenic (TG) mouse model. Again, rAAV1-HGF not only improved motor performance but also increased the survival rate. Moreover, the number and diameter of spinal motor neurons (SMNs) were increased, and the shape of the NMJs restored. Data from in vitro motor cortical culture experiments indicated that treatment with recombinant HGF protein (rHGF) increased the axon length of corticospinal motor neurons (CSMNs). When cultures were treated with an ERK inhibitor, the effects of HGF on axon elongation, protein aggregation, and oxidative stress were suppressed, indicating that ERK phosphorylation played an important role(s). Taken together, our results suggested that HGF might play an important role(s) in delaying disease progression in the SOD1-G93A TG mouse model by reducing oxidative stress through the control of ERK phosphorylation.
\end{abstract}

Keywords: Amyotrophic lateral sclerosis (ALS), Adeno-associated virus (AAV), Hepatocyte growth factor (HGF) Corticospinal motor neuron (CSMN), Oxidative stress

\footnotetext{
*Correspondence: sk@helixmith.com

${ }^{1}$ R\&D Center for Innovative Medicines, Helixmith Co., Ltd., Building 203,

Gwanak-Gu, Seoul 08826, Korea

Full list of author information is available at the end of the article
}

(c) The Author(s). 2019 Open Access This article is distributed under the terms of the Creative Commons Attribution 4.0 International License (http://creativecommons.org/licenses/by/4.0/), which permits unrestricted use, distribution, and reproduction in any medium, provided you give appropriate credit to the original author(s) and the source, provide a link to the Creative Commons license, and indicate if changes were made. The Creative Commons Public Domain Dedication waiver (http://creativecommons.org/publicdomain/zero/1.0/) applies to the data made available in this article, unless otherwise stated. 


\section{Introduction}

ALS is a neurodegenerative disease, in which the motor neurons of the central nervous system degenerate progressively $[13,23,49]$. A variety of chemicals, recombinant proteins, and gene therapies have been explored to develop treatment methods for ALS, but to date, only two small molecules, riluzole and edaravone, have been approved by the FDA $[3,5,39]$. Their therapeutic effects are relatively low: riluzole delays the time to tracheostomy by 2 to 3 months, and edaravone improves the ALSFRS-R score by 33\%. There is still a high unmet need for a medical solution to this fatal disease.

In this study, we investigated whether HGF could be used to treat ALS in the context of AAV-based gene therapy. Since its discovery in 1984, HGF has been shown to contain multiple bioactivities, promoting cell proliferation, morphogenesis, anti-fibrosis, anti-inflammation, and angiogenesis, among others [17, 28, 31, 32, 40, 52, 57]. When HGF binds to the Met receptor, a variety of intracellular signaling pathways are activated, involving PI3K, JNK, p38, and/or ERK, triggering different biological reactions depending on the cell type $[36,37,50]$. HGF is also a neurotrophic factor in that it can induce the development, proliferation, and differentiation of neuronal cells [19, 30, $34,41,45,46]$. It has also been reported that the HGF-Met complex was abnormally sequestered in fALS patients [20]. In the SOD1-G93A TG mouse model, disease progression has been delayed when HGF or Met expression was additionally introduced by generating double TG mice, or when rHGF was intrathecally delivered, indicating that HGF might play an important role(s) in ALS $[10,16,48]$.

HGF-expressing plasmid DNA was used in the phase I trial for ALS [47]. A single intramuscular administration of this plasmid DNA in 18 ALS patients has been proven to be safe, with no significant adverse effects. According to the ALSFRS-R scores, the conditions of patients appeared to stabilize or even improve in $50 \%$ of patients-albeit temporarily-during the first 2 to 3 months following injection. The same plasmid was also used for diabetic peripheral neuropathy and critical limb ischemia, and generated highly positive results with virtually no drug-related adverse effects, indicating the possibility of employing plasmid DNA expressing HGF for a broad range of neuromuscular or neuroischemic diseases [1, 11, 14, 21, 22].

This study employed AAV, as an alternative method of delivering the HGF gene $[7,59]$. AAV can drive relatively long-term expression in vivo and deliver the transgene to a variety of cell types, including non-dividing cells through capsid pseudotyping [7]. We found that among 4 serotypes tested, serotype 1 (rAAV1) most effectively delivered the gene to the ventral horn of the LSC when introduced to the subarachnoid space by IT delivery. When evaluated in two mouse models-the sciatic nerve crush and SOD1-G93A TG mouse modelsrAAV1-HGF ameliorated deficits in motor functions as measured by several behavioral tests and regenerated impaired NMJ structure [53]. Consistent with these observations, HGF was found to increase the axon lengths of CSMNs in vitro. Data from experiments involving specific chemical inhibitors revealed that phosphorylation of ERK is an important player for HGF-generated effects. Our results suggested that the HGF gene may be a good starting point for developing therapeutic agents for ALS and that rAAV vector in particular might be a useful gene delivery vehicle.

\section{Materials \& methods \\ Animals}

C57BL/6 mice were purchased from Orient Bio Inc. (Gyeonggi-do, Korea). B6SJL-TG(SOD1-G93A)1Gur/J mice (MGI ID: 2183719) were purchased from The Jackson Laboratory [12, 51, 55]. Mice were fed ad libitum and entrained to a standard light-dark cycle. All experimental protocols adhered to the regulations of the Seoul National University Institutional Animal Care and Use Committee (IACUC).

\section{Adeno-associated virus}

In this study, a gDNA-cDNA-hybrid sequence that could express HGF723 (dHGF) and HGF728 (cHGF) was generated using human genomic DNA as previously described [6, 38]. This hybrid sequence has cDNA sequences of 18 exons of the HGF gene, containing a part of intron 4 between exon 4 and exon 5 . Since the length of intron 4 is too long to produce viral vectors, 4329 base pairs of intron 4 were deleted using site-directed mutagenesis by polymerase chain reaction (PCR). This chimeric sequence was then inserted into the ITR (inverted terminal repeat) region of pAAV-MCS, a plasmid containing multiple cloning sites purchased from Agilent Technologies, to generate pAAV-HGF. To produce rAAV2-HGF, equal amounts of three plasmids (rep/cap-expressing plasmid, pAAV-HGF, and helper plasmid) were co-transfected into $1 \times 10^{6}$ HEK293T cells using AAV Helper-Free System (Agilent Technologies). $1.23 \times 10^{8}$ GC (genome copies) of rAAV2-HGF were then transduced into $1.6 \times 10^{5} \mathrm{C} 2 \mathrm{C} 12$ cells. Forty-eight hours later, the supernatant was collected followed by ELISA specific to human HGF (hHGF). At the same time, total RNAs were isolated and subjected to RT-PCR using Expand High Fidelity PCR System (Sigma). Primers used for PCR were as follows; 5' -CAAATGTCAGCCCTGGAGTTCCATGA-3' (forward); 5'-CTGGATTGCTTGTGAAACACCAGGGT-3' (reverse). PCR products were then run on NuPAGE 4$12 \%$ Bis-Tris Protein Gels (Thermofisher). rAAV2-MCS lacking the HGF sequence (rAAV2-C) was used as a 
negative control. For animal studies, rAAV (serotype 1, 2,5 , and 6) with a higher titer $\left(1 \times 10^{12} \mathrm{GC} / \mathrm{ml}\right)$ was produced by a contract manufacturing company called CdmoGen (Chungbuk, Korea).

\section{Sciatic nerve crush}

The sciatic nerves of C57BL/6 mice were exposed, and nerve crush injury was induced with fine hemostatic forceps (FST), as described previously $[6,24]$. Mice were exposed to isoflurane at $4-5 \%$ until anesthesia was induced, with concentration reduced to $1.5 \%$ during surgery. Behavioral tests were performed once a week for four weeks. For histological analysis, the sciatic nerves and tibialis anterior (TA) muscles were collected five days after surgery.

\section{Behavioral tests}

The motor function of mice was evaluated using the rotarod test, wire hanging test, and grip strength test. For the rotarod test, the latency to fall from the rotating rod was recorded. The speed of the rod was accelerated from $4 \mathrm{rpm}$ to $40 \mathrm{rpm}$ for $5 \mathrm{~min}$, as described previously $[15,25,44]$. For the wire hanging test, mice were placed upside down under wire mesh. The latency to fall was recorded. The maximum latency was set to $1 \mathrm{~min}$. Grip strengths of the forelimb and hindlimb were measured with a grip strength meter (Nidec-Shimpo). Mice were pre-trained for a week for each behavioral test. Each test was performed three times and values were averaged.

\section{Primary motor cortical cultures}

Cerebral motor cortices of mice were isolated, and cells were incubated as described previously [18]. Six-well cell culture plates (SPL) pre-coated with $0.1 \mathrm{mg} / \mathrm{ml}$ of PDL (Sigma) were incubated overnight at $37^{\circ} \mathrm{C}$, followed by two washings with distilled water (Sigma). Motor cortices of non-TG or TG mice at P3 were collected using fine forceps (FST) into dissociation solution (DS) containing magnesium chloride (Sigma), Hepes (Gibco), sodium sulfate (Sigma), potassium sulfate (Sigma), kyneuric acid (Sigma), glucose (Sigma), APV (Sigma), penicillin/streptomycin (P/S) (Gibco), and B27 (Gibco). Cells were then dissociated in a papain solution (Worthington Biochem) for $15 \mathrm{~min}$, and incubated in inhibitor solution containing ovomucoid (Sigma) for 1 min. After being washed with Opti-MEM (Gibco) solution containing APV (Sigma) and B27, $3.2 \times 10^{5}$ cells were seeded with serum-free media (SFM) containing BSA, L-glutamine (Sigma), P/S, glucose, and B27 in neurobasal media (Gibco). Cells were then treated with inhibitors for Met (PHA665752), ERK (U0126), PI3K (LY294002), p38 (SB203580), and JNK (SP600125). Thirty minutes later, cells were cultured in the presence of $100 \mathrm{ng} / \mathrm{ml}$ of rHGF (R\&D Systems). 3 days later, cells were subjected to immunocytochemistry (ICC) assay.

\section{Western blot}

Total proteins were isolated using RIPA Buffer (Cell Signaling Technology) and Protease/Phosphatase Inhibitor Cocktail (Cell Signaling Technology), followed by polyacrylamide gel electrophoresis on NuPAGE 4-12\% Bis-Tris Protein Gels (Thermofisher) using 10-20 $\mu \mathrm{g}$ of protein. Gels were transferred to the PVDF membrane (GE Healthcare) and blocked with 0.1\% TBST solution containing 5\% skim milk (Difco) for $1 \mathrm{~h}$. Membranes were incubated with $0.1 \%$ TBST solution containing $5 \%$ BSA and primary antibodies for $1 \mathrm{~h}$, then treated with $0.1 \%$ TBST solution containing 5\% skim milk for $1 \mathrm{~h}$. HRP conjugated anti-rabbit or anti-mouse IgG (Sigma) was used as a secondary antibody. Membranes were incubated with Immobilin Western Chemiluminescent HRP Substrate (Millipore) for $1 \mathrm{~min}$ and developed on $\mathrm{X}$-ray film (AGFA).

\section{Immunohistochemistry (IHC)}

The sciatic nerves, LSCs, and TA muscles were fixed in $4 \%$ paraformaldehyde (Sigma) at $4{ }^{\circ} \mathrm{C}$ overnight. After being washed three times with $0.1 \mathrm{M} \mathrm{PBS}$, the tissues were immersed in $0.1 \mathrm{M}$ PBS containing 30\% sucrose (Sigma) at $4{ }^{\circ} \mathrm{C}$ overnight, followed by cryopreservation in OCT compound (Sakura Tissue Tek). Samples were then cryosectioned using Cryostat (Leica). After $1 \mathrm{~h}$ incubation in blocking solution containing $2 \%$ BSA, $5 \%$ normal donkey serum (Jackson ImmunoResearch), and $0.1 \%$ Triton X-100 (Samchun), samples were treated with blocking solution containing primary antibodies for $1 \mathrm{~h}$, and then with blocking solution containing secondary antibodies for $1 \mathrm{~h}$. IgG Alexa Fluor (Invitrogen) was used as a secondary antibody. After mounting tissue sections on microscope slides (Fisher Scientific) with DAPI (Vectashield), immunofluorescence was observed using LSM 700 confocal laser scanning microscopy (Carl Zeiss).

\section{Immunocytochemistry (ICC)}

Cells were fixed in $4 \%$ paraformaldehyde for $10 \mathrm{~min}$ at room temperature. After being washed three times with PBS, cells were immersed in $0.1 \mathrm{M}$ PBS containing $2 \%$ Triton X-100 for $5 \mathrm{~min}$ at $4{ }^{\circ} \mathrm{C}$, followed by one hour incubation in blocking solution with $2 \%$ normal donkey serum and 1\% BSA. Cells were then treated with blocking solution containing primary antibodies for $1 \mathrm{~h}$, followed by another 1-h incubation in blocking solution with secondary antibodies. IgG Alexa Fluor was used as a secondary antibody. After mounting cells on microscope slides with DAPI, immunofluorescence was observed using LSM 700 confocal laser scanning 
microscopy. The axon length of CSMNs was measured using Fiji software (NIH).

\section{Quantitative real time PCR (q-RTPCR)}

The transgene copy number of SOD1-G93A TG mice was measured using q-RTPCR, as described previously [2]. For transgene (hSOD1), the primers used for PCR were as follows; 5'-CATCAGCCCTAATCCATCTGA-3' (forward); 5'-CGCGACTAACAATCAAAGTGA-3' (reverse). For reference gene (IL2), the primers used for PCR were as follows; 5'-CTAGGCCACAGAATTGAAAGATCT-3' (forward); 5'-GTAGGTGGAAATTCTAGCATCATCC-3' (reverse). After 40 cycles of qPCR using TB Green (Takara), the difference of threshold cycle $(\triangle C T)$ was calculated, and mice with values between 6.6 and 7.2 were used.

\section{Cell viability assay}

$1.6 \times 10^{5}$ cells were seeded on PDL-coated 48-well cell culture plates (SPL) and incubated for 3 days. After being washed two times with warm PBS, cells were incubated with SFM containing 10\% WST1 (AbFrontier) for $1 \mathrm{~h}$ at $37^{\circ} \mathrm{C}$. Absorbance was measured at $440 \mathrm{~nm}$ using a Magellan microplate reader (Tecan).

\section{Enzyme-linked immunosorbent assay (ELISA)}

To measure the HGF protein level in vitro, $1.6 \times 10^{5}$ $\mathrm{C} 2 \mathrm{C} 12$ cells were transduced with $5 \times 10^{13} \mathrm{GC}$ of rAAV2-HGF. Forty-eight hours later, supernatants were collected followed by ELISA specific to human HGF (R\&D Systems). To measure the in vivo expression of HGF, C57BL/6 P60 mice were intrathecally injected with $5 \times 10^{9}$ GC of rAAV1-HGF. The LSCs were collected 1, $2,4,8,12$, and 16 weeks after injection. Total proteins were then extracted using RIPA Buffer and Protease/ Phosphatase Inhibitor Cocktail, followed by ELISA for hHGF. Absorbance was measured at $450 \mathrm{~nm}$, and wavelength correction was made at $540 \mathrm{~nm}$ using a Magellan microplate reader.

\section{Reactive oxygen species (ROS) detection assay}

$6.4 \times 10^{4}$ cells were seeded on PDL-coated 96-well cell culture plates (Nunc) and incubated for 3 days. ROS levels were measured using a ROS Detection Assay Kit (Abcam). Cells were incubated with detection solution for $1 \mathrm{~h}$ at $37^{\circ} \mathrm{C}$. Pyocianin was used as a ROS inducer, while $\mathrm{N}$-acetyl-L-cysteine was used as a ROS scavenger. Absorbance was measured using a Magellan microplate reader.

\section{Microarray assay}

Motor cortical cells were treated with $100 \mathrm{ng} / \mathrm{ml}$ of rHGF, and total RNAs were isolated followed by Microarray analysis using Affymetrix Genechip (Thermofisher).
After data extraction, RMA (robust multi-array average) normalization was performed, followed by DEG (differentially expressed gene) analysis. Out of selected DEGs, functional annotation was performed based on GO (gene ontologies) hierarchy and KEGG/BioCarta pathways. Selected genes were clustered according to the classification from the previous report [49].

\section{Statistical analysis}

All values are presented as mean \pm standard error mean (SEM). Differences between two values were analyzed by Student's t-tests. Differences between three or more values were analyzed by one-way ANOVA followed by Tukey's post-hoc test. For values containing temporal factors, two-way ANOVA was performed followed by Tukey or Sidak's post-hoc test.

\section{Results}

\section{Construction of rAAV vectors expressing human HGF}

In this study, we tested whether an HGF-expressing rAAV vector could facilitate the regeneration of motor neurons and alleviate disease progression of ALS when delivered to the subarachnoid space through IT injection. AAV used in this study was designed to express two isoforms of human HGF-HGF723 (or dHGF) and HGF728 (or cHGF) - as in the case of our bodies [6]. In order to simultaneously express two isoforms, we used the gDNA-cDNA-hybrid sequence similar to that described by Cho et al. (Additional file 1: Figure S1a). This chimeric sequence was inserted into PAAV-MCS containing multiple cloning sites, resulting in pAAV-HGF.

To produce rAAV vectors, equal amounts of three plasmids (pAAV-HGF, rep/cap-expressing plasmid, and helper plasmid) were co-transfected into $1 \times 10^{6}$ HEK293T cells, initially producing AAV serotype 2 [4]. Seventy-two hours later, the supernatant was collected and viral titer was determined as described previously [29]. To determine whether rAAV vectors could indeed produce RNAs of two HGF isoforms, $1.6 \times 10^{5} \mathrm{C} 2 \mathrm{C} 12$ cells were transduced with $1.23 \times 10^{8} \mathrm{GC}$ of rAAV, and total RNAs were isolated $48 \mathrm{~h}$ later followed by RT-PCR. A control virus-rAAV2-C lacking the HGF sequencedid not produce any HGF RNA, whereas two HGF RNA species, each for HGF723 and HGF728, were readily detectable in cells transduced with rAAV2-HGF (Additional file 1: Figure S1b).

To test whether HGF proteins were indeed produced from rAAV vectors, $8 \times 10^{4} \mathrm{C} 2 \mathrm{C} 12$ cells were transduced with $5 \times 10^{13} \mathrm{GC}$ of rAAV, and total proteins were isolated $48 \mathrm{~h}$ later followed by ELISA specific to human HGF proteins. rAAV2-HGF produced $159.13 \pm 23.92 \mathrm{ng} / \mathrm{mg}$ of HGF, while no HGF was detectable in cells transduced with a control vector. (Additional file 1: Figure S1c). 


\section{Comparison of four AAV serotypes}

Different subtypes of AAV have been shown to possess different tropism. To select an appropriate AAV serotype that could be used for gene transfer to the spinal cord, four serotypes of AAV (rAAV-1, - 2, -5, and -6) were prepared as described above, and $4.12 \times 10^{8} \mathrm{GC}$ of each AAV were injected into the LSC. Four weeks later, total proteins were extracted from the LSC, and the expression level of HGF was compared using ELISA. As summarized in Fig. 1a, mice injected with rAAV1-HGF produced the highest level of HGF protein $(621.89 \pm$ $112.98 \mathrm{pg} / \mathrm{mg}$ ), and other serotypes generated 7- to 17 -fold lower amounts, $86.25 \pm 7.59 \mathrm{pg} / \mathrm{mg}$ for rAAV6, $35.54 \pm 4.87 \mathrm{pg} / \mathrm{mg}$ for $\mathrm{rAAV} 2$, and $80.15 \pm 17.94 \mathrm{pg} / \mathrm{mg}$ for rAAV5 (Fig. 1a).

To determine the tissue distribution of transgene expression from different AAV vectors inside the LSC, different subtypes of AAV expressing GFP were used because it was technically difficult to analyze human HGF by IHC. Four weeks after IT injection of AAV vectors, tissue samples were taken and GFP-expressing cells were measured by IHC. rAAV1-GFP transduced the largest area of the ventral horn, while rAAV2 or rAAV6 expressed GFP primarily on the surface of white matter (Fig. 1b). Taken together, AAV1 appeared to be the most effective serotype for IT gene delivery, and thus was used for further experiments.

\section{Kinetics of HGF expression from rAAV1-HGF}

To determine how the HGF expression level changed over time, $5 \times 10^{9} \mathrm{GC}$ of rAAV1-HGF were injected into the LSC of 2-month-old C57BL/6 mice, and total proteins were isolated, followed by ELISA. One week after injection, $1.98 \pm 0.95 \mathrm{ng} / \mathrm{mg}$ of hHGF were detectable, and the level was the highest after two weeks $(2.44 \pm 1.37 \mathrm{ng} / \mathrm{mg})$, thereafter gradually decreasing over time until 16 weeks after injection $(0.95 \pm 0.58 \mathrm{ng} / \mathrm{mg})$ (Fig. 1c). A control virus lacking the HGF sequence did not produce any HGF protein. While hHGF was not detectable in the motor cortex and serum, $170.17 \pm 155.95 \mathrm{pg} / \mathrm{mg}$ were observed in the TA (Additional file 1: Figure S1d).

To investigate whether the HGF proteins expressed from rAAV1-HGF could increase the phosphorylation of Met, a receptor for HGF, $5 \times 10^{9}$ GC of rAAV1-HGF were intrathecally injected into C57BL/6 mice at P60, Met phosphorylation levels were measured 7 days later using IHC. As shown in Fig. 1d, SMNs were labeled with NeuN (red) and ChAT (green). In mice injected with rAAV1-C, $37.32 \pm 0.02 \%$ of SMNs were co-stained with p-Met. The number of p-Met-positive SMNs was increased to $58.09 \pm 0.01 \%$ in the rAAV1-HGF group
(Fig. 2e). These results indicated that HGF proteins expressed from rAAV1-HGF could indeed augment the phosphorylation of Met.

\section{Effects of rAAV1-HGF on the sciatic nerve crush model}

We first used the sciatic nerve crush mouse model to quickly check the effects of intrathecally delivered rAAV1-HGF on nerve damage in general [53]. Crush injury was introduced in 2-month-old C57BL/6 mice, and $5 \times 10^{9} \mathrm{GC}$ of virus were intrathecally injected immediately. As shown in Fig. 2a-b, rAAV1-HGF significantly improved hindlimb strength and rotarod performance from 10 days after nerve crush, and these effects were maintained until the end of the experiment on day 28 . These results suggested that rAAV1-HGF could promote functional recovery after sciatic nerve crush when delivered into the spinal cord.

It is well established that when the sciatic nerve is injured, Wallerian degeneration occurs and axons regenerate again as time goes by [42]. Therefore, we used IHC to examine whether rAAV1-HGF had effects on nerve regeneration in the areas of the nerve damage. Five days after nerve injury, the sciatic nerve was collected, and labeled with SCG10, a marker for the regenerating axon [43]. When the length of the regenerated sciatic nerve was measured, rAAV1-C showed a $2.11 \pm 0.09 \mathrm{~mm}$ increase from the damaged site, while in the rAAV1-HGF group, it was $37.91 \%$ higher at $2.91 \pm 0.27 \mathrm{~mm}$ (Fig. $2 \mathrm{c}-\mathrm{d}$ ).

The presynaptic terminal of the sciatic nerve forms NMJs with the postsynaptic end plate of the muscle to transmit the contractile signal to the muscle [53]. Therefore, TA muscle connected to the sciatic nerve was analyzed by IHC. In a normal state, the NMJ is pretzel-shaped and has well-preserved integrity. After nerve injury, however, the shape of the NMJ becomes abnormal and the degree of integrity decreases (Fig. 2e-f). Compared with the sham group to which the nerve injury was not introduced, the proportion of fully innervated NMJs in the rAAV1-C group was reduced 2.34-fold, and that of abnormally shaped NMJs was increased 7.75-fold. On the other hand, in the rAAV1-HGF group, the proportion of fully innervated NMJs increased by $69.7 \%$, and that of denervated NMJs decreased 3.83-fold in comparison to the rAAV1-C group (Fig. 2g-h). The average $\alpha$-BTX area was decreased by $41.75 \%$ in the rAAV1-C group compared to the sham group, but was increased by $56.76 \%$ in the rAAV1-HGF group. These results suggested that IT injection of rAAV1-HGF could promote the regeneration of neurons and re-establishment of NMJs possibly by acting on the cell body of motor neurons located in the spinal cord.

\section{Effects of rAAV1-HGF in SOD1-G93A TG mouse model}

Encouraged by the above results, the effects of rAAV1-HGF were also tested in the SOD1-G93A TG 


\section{a}
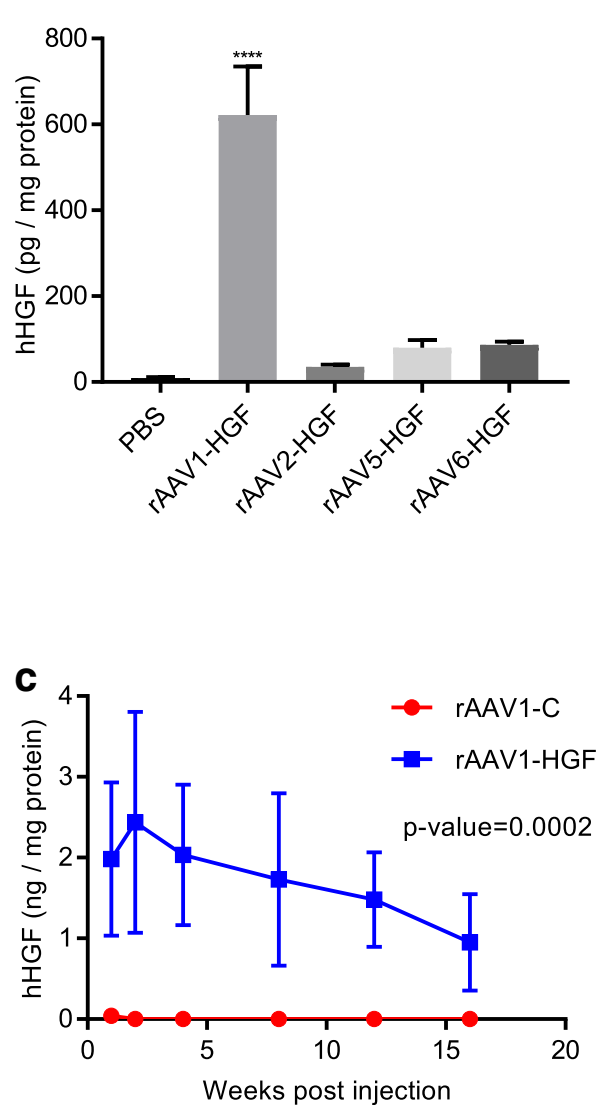

b

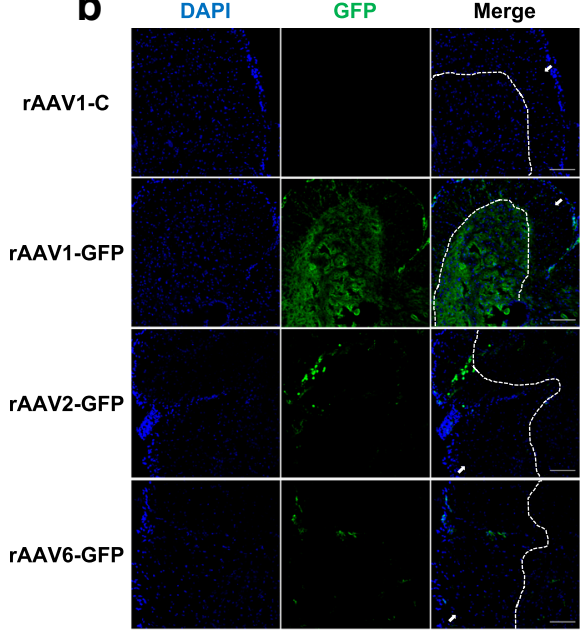

e

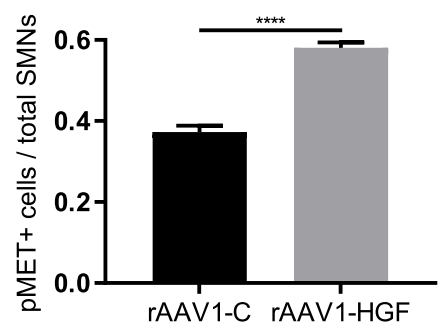

d

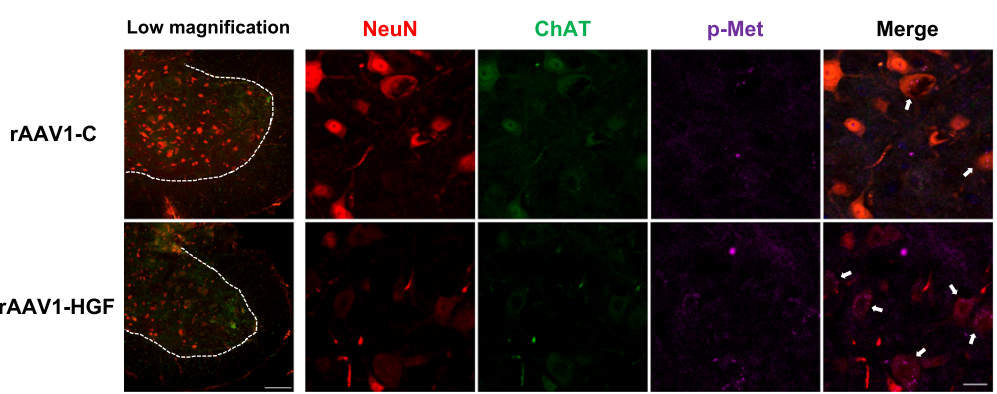

Fig. 1 IT administration of rAAV1-HGF promoted functional recovery in the sciatic nerve crush mouse model. a $4.12 \times 10^{8}$ GC of rAAV1, 2, 5, or 6HGF were intrathecally injected into C57BL/6 mice at postnatal day 60 (P60). The LSCs were collected and total proteins were isolated 4 weeks after injection, followed by ELISA specific to human HGF (hHGF). For statistical analysis, one-way ANOVA was performed, followed by Tukey's post-hoc test. ${ }^{* * * *} p<0.0001$ for rAAV1 vs. other serotypes. b $1.4 \times 10^{9} \mathrm{GC}$ of four serotypes were intrathecally injected into 2-month-old C57BL/6 mice. The LSCs were collected 4 weeks after injection. Tissues were fixed, followed by IHC assay using an antibody specific to GFP (green). The boundary between white and grey matter is distinguished by dotted lines, and white matter is indicated by white arrows. c $5 \times 10^{9} \mathrm{GC}$ of rAAV1HGF were intrathecally injected into 2-month-old C57BL/6 mice. The LSCs were collected 1, 2, 4, 8, 12, and 16 weeks after IT injection and subjected to ELISA for hHGF. For statistical analysis, two-way ANOVA was performed, followed by Sidak's post-hoc test. The $p$-value between the two groups was 0.0002 . d C57BL/6 mice at P60 were intrathecally injected with $5 \times 10^{9}$ GC of rAAV1-C or rAAV1-HGF. One week later, LSCs were collected and subjected to IHC assay. Antibodies specific to ChAT (green) and NeuN (red) were used to label SMNs, together with those for pMet (magenta). In low magnification panels, the boundary between white and grey matter is distinguished by dotted lines. In merge panels, pMet-expressing SMNs are indicated by white arrows. e The proportion of SMNs expressing p-Met per total SMNs was measured and represented as a bar graph. For statistical analysis, Student's t-test was performed. ${ }^{* * *} p<0.0001$. In bar graphs, values are represented as mean \pm SEM. Scale bar: $\mathbf{b}=100 \mu \mathrm{m}, \mathbf{d}=100 \mu \mathrm{m}$ for low magnification panels and $20 \mu \mathrm{m}$ for the others 

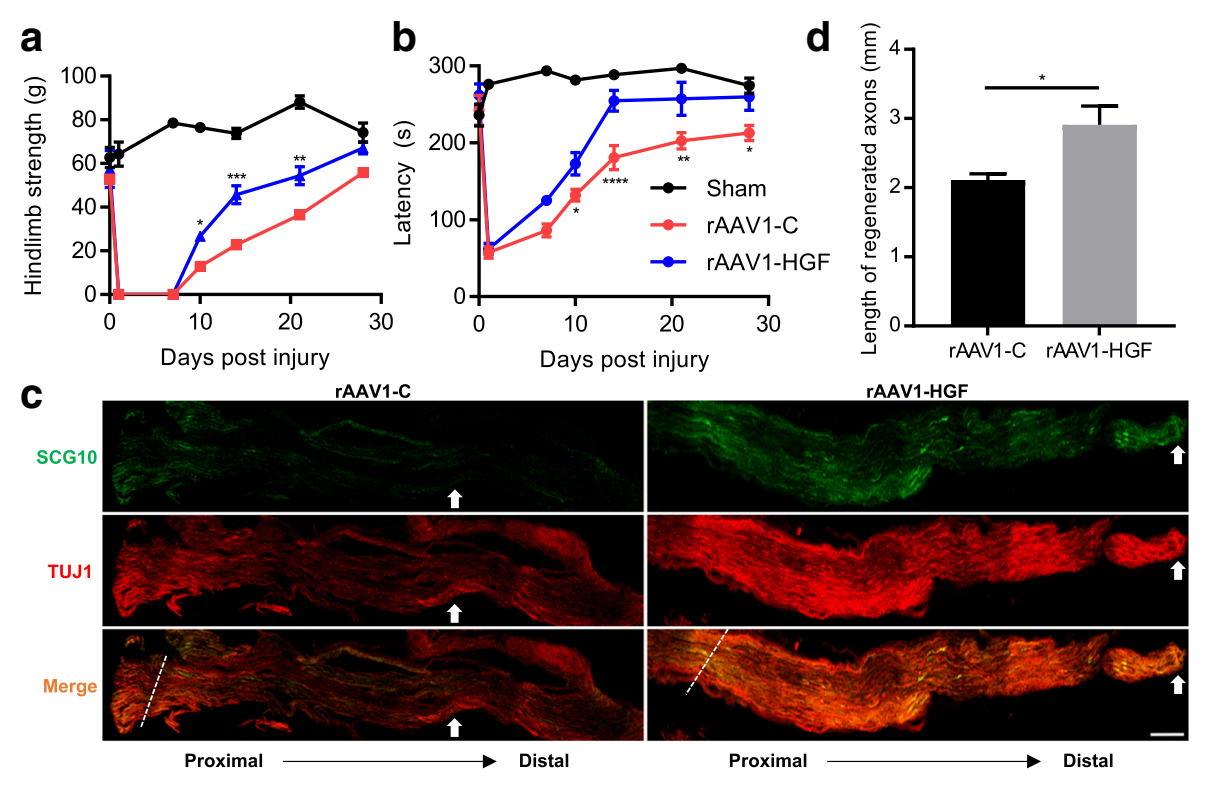

Days post injury rAAV1-HGF

e

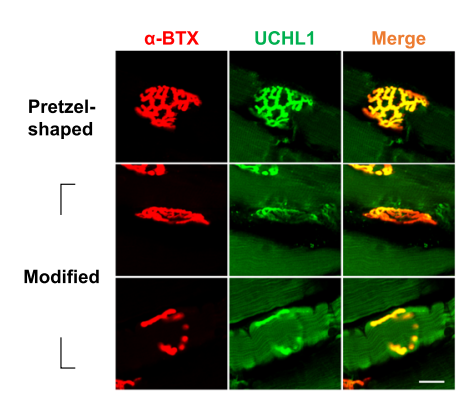

f
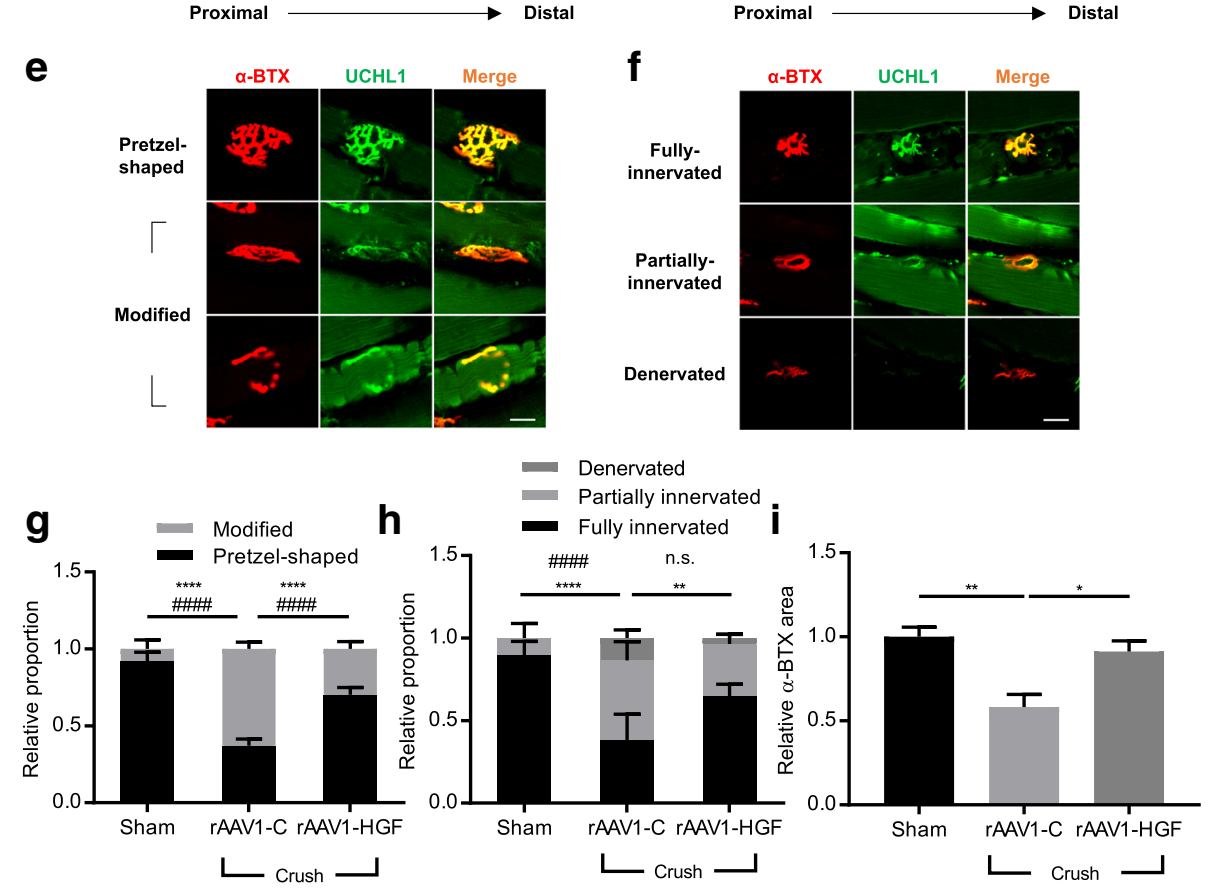

Fig. 2 (See legend on next page.) 


\section{(See figure on previous page.)}

Fig. 2 IT delivery of rAAV1-HGF facilitated the regeneration of the sciatic nerves and TA muscles after sciatic nerve crush. a-h Using 2-month-old C57BL/6 mice, sciatic nerve crush was induced, and $5 \times 10^{11} \mathrm{GC}$ of rAAV1-C or rAAV1-HGF were intrathecally injected into the LSC. Behavioral tests were performed once a week for 28 days $(\mathbf{a}-\mathbf{b})$. For IHC assay, the sciatic nerves and TA muscles were collected 5 days after nerve crush (c-f). a Hindlimb strength was measured 1, 7, 10, 14, 21, and 28 days after nerve crush. Value at day 0 was measured before nerve crush. $\mathbf{b}$ Mean latency to fall from the rotarod was measured 1, 7, 10, 14, 21, and 27 days after nerve crush. Value at day 0 was measured before nerve crush. In Fig. 2a-b, two-way ANOVA was performed, followed by Tukey's post-hoc test. c Representative images of the sciatic nerves from mice treated with rAAV1-C or rAAV1-HGF after nerve crush. Antibodies specific to TUJ1 and SCG10 were used as markers for neurons and regenerating axons, respectively. Crush sites are indicated by dotted lines, and the tip of SCG10 signals is indicated by white arrows. Proximodistal direction is indicated by dotted lines. $\mathbf{d}$ After sciatic nerve crush, lengths of regenerated nerves were measured using Fiji software and represented as a bar graph. For statistical analysis, Student's t-test was performed. e-f An antibody specific to UCHL1 was used as a marker for presynaptic terminals, whereas that of a-bungarotoxin (a-BTX) was used for postsynaptic end plates [9]. The shapes of NMJs were analyzed to determine whether they were pretzel-shaped or distorted (e). The integrity of NMJs was determined by measuring to what degree presynaptic terminals merged with postsynaptic end plates (f). $\mathbf{g}$-i After sciatic nerve crush, the shape $(\mathbf{g})$ and integrity (h) of NMJs and average a-BTX area (i) were measured. For graphs, values are represented as mean \pm SEM. In Fig. 2g-h, two-way ANOVA was performed, followed by Tukey's post-hoc test. In Fig. 2g, ${ }_{* * * *}^{*} p<0.0001$ for modified NMJ, ${ }^{\# \# \# \#} p<0.0001$ for pretzel-shaped NMJ. In Fig. $2 \mathrm{~h},{ }^{* *} p<0.01$ and ${ }^{* * * *} p<0.0001$ for fully innervated NMJ, $\# \# \#<0.0001$ and n.s. $>0.05$ partially innervated NMJ. In Fig. 2i, one-way ANOVA was performed, followed by Tukey's post-hoc test. For the remaining bar graphs, ${ }^{*} p<0.05,{ }^{* *} p<0.005,{ }^{* * *} p<0.001,{ }^{* * * *} p<0.0001$. Scale bars: $\mathbf{c}=200 \mu \mathrm{m} ; \mathbf{d}-\mathbf{e}=20 \mu \mathrm{m}$

mouse model, the most commonly used animal model for ALS. First, we investigated whether HGF proteins expressed from rAAV1-HGF could also increase the phosphorylation of Met in SOD1-G93A TG mice. $5 \times 10^{9} \mathrm{GC}$ of rAAV1-HGF were intrathecally injected to SOD1-G93A TG mice at P60, and the levels of Met phosphorylation were measured 40 days later using IHC (Additional file 1: Figure S2a). In non-TG mice, $35.24 \pm 0.55 \%$ of SMNs were co-stained with p-Met. The number of p-Met-positive cells was lowered in TG mice injected with a control vector, rAAV1-C, to $29.98 \pm 0.54 \%$, but increased to $59.65 \pm 1.35 \%$ in the rAAV1-HGF group (Additional file 1: Figure S2b). These findings suggested that the HGF proteins expressed from rAAV1-HGF could indeed increase the phosphorylation of Met in this mouse model.

To test whether rAAV1-HGF could exert any effect on disease progression of SOD1-G93A TG mice, body weight was measured and behavioral tests were performed once every week until P158 after injecting rAAV1-HGF into the LSC of TG mice at P60. IT delivery of rAAV1-HGF did not affect the rate of weight loss (Fig. 3e), but significant improvements were observed in rotarod, hanging wire, and grip strength tests (Fig. 3a-d). In addition, survival rate was increased from 20 to $66.67 \%$ at P150, and median survival was also increased by $6.53 \%$ from 145.5 days to 155 days (Fig. 3f). These results suggested that IT delivery of rAAV1-HGF might slow disease progression and improve survival rate in this mouse model.

\section{Effects of rAAV1-HGF on SMNs and NMJs in the SOD1- G93A TG mouse model}

We tested whether IT injection of rAAV1-HGF could delay degeneration of SMNs in SOD1-G93A TG mice. $5 \times 10^{9}$ GC of rAAV1-HGF were injected into the LSCs of SOD1-G93A TG mice at P60, and the LSCs were collected 40 days later (P100) followed by IHC. When compared to the non-TG group, the rAAV1-C group showed the number of SMNs in the ventral horn reduced 2.07-fold, the ratio of SMNs to total cells decreased by $58.65 \%$, and the diameter of SMNs diminished by $39.83 \%$ (Fig. 4a). Although rAAV1-HGF did not increase the diameter of SMNs, the number of SMNs was increased 2.36-fold and the ratio of SMNs to total cells was increased by $67.11 \%$, compared to the rAAV1-C (Fig. 4b-d).

We also examined whether changes in SMNs by the rAAV1-HGF could lead to improvements in connected axon terminals and muscles. Similar to the experiments described above (Fig. 2e-h), the NMJ was observed and the weight of TA was measured. Compared to the non-TG group, in the rAAV1-C group, the proportion of fully innervated NMJs was decreased by $25.48 \%$, the level of abnormal-shaped NMJs was increased 3.5-fold, and the weight of TA was decreased by $35.42 \%$. When rAAV1-HGF was injected, however, the proportion of pretzel-shaped NMJs was increased by $32.58 \%$ (Fig. $4 \mathrm{e}-\mathrm{f}$ ), and the weight of TA, which was decreased by muscular atrophy in the rAAV1-C group, was increased by $38.42 \%$ (Fig. $4 \mathrm{~g}$ ). No visible change was observed in the degree of NMJ integrity in the rAAV1-HGF group. These results indicated that IT delivery of rAAV1-HGF could promote the protection of peripheral nerves and NMJs as well as SMNs.

\section{Effects of rHGF on axonal outgrowth of CSMNs}

The above data showed that IT delivery of rAAV1-HGF could improve motor functions and survival rates of SOD1-G93A TG mice, presumably by slowing down the degeneration of SMNs and restoring the morphology of NMJs. Since the interaction of HGF with lower motor neurons has been relatively well established compared to the interaction of HGF with upper motor neurons 


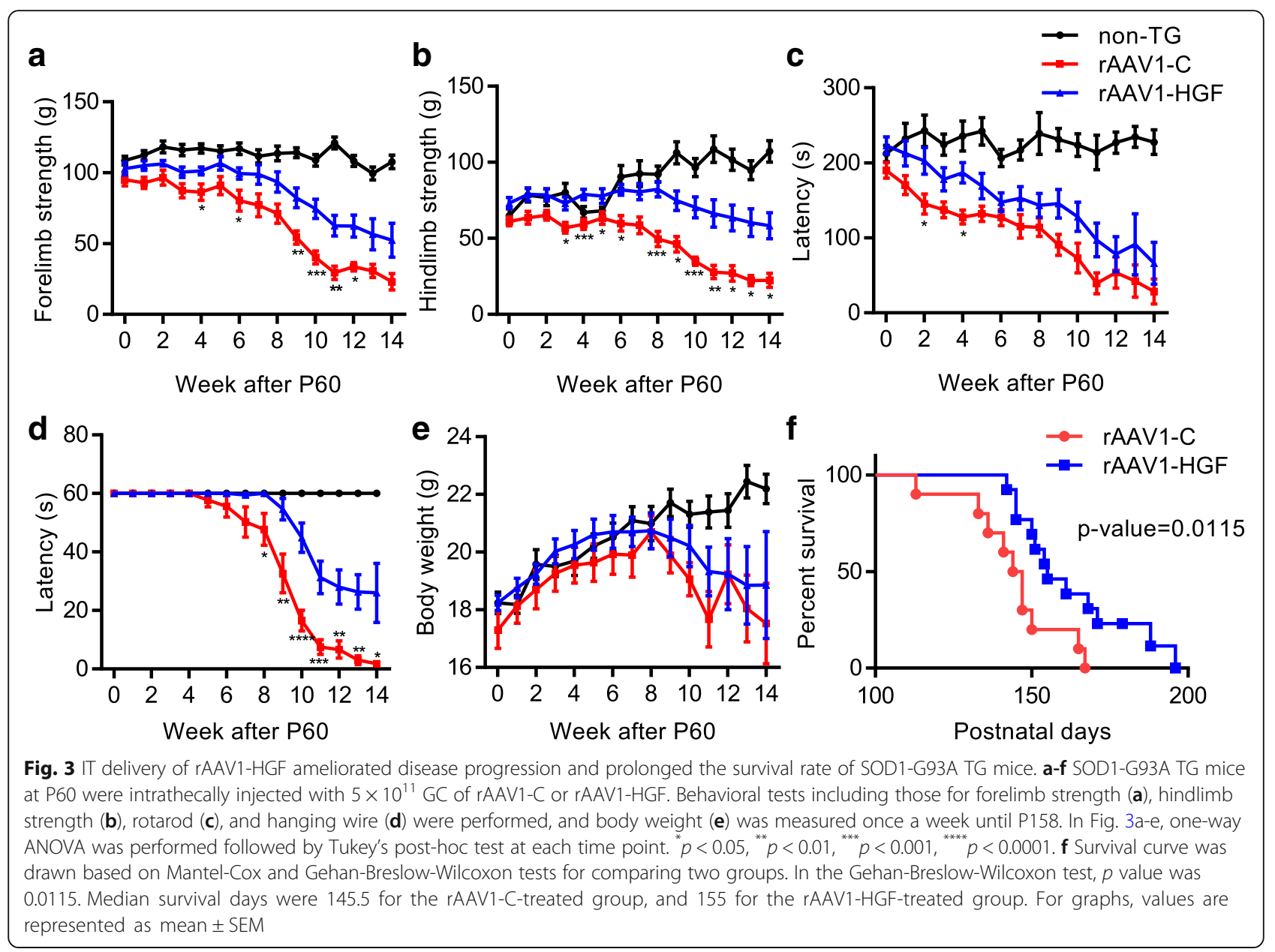

$[8,54,56]$, we were interested in testing the possible involvement of upper motor neurons by using the motor cortical cultures system consisting of CSMNs and glial cells [18, 35].

The motor cortices were isolated from P3 non-TG or TG mice, and $2 \times 10^{4}$ cells were cultured on a 24-well plate. Three days later, cells were fixed, followed by IHC analysis. CSMNs were labeled with UCHL1 and Ctip2, and Fiji software was used to measure the axon length of CSMNs [58] (Fig. 5a).

Since CSMNs have previously been shown to produce HGF which may give experimental noise, the effects of endogenously expressed HGF were first tested using PHA665752, a chemical inhibitor of Met. When cells were treated with $1 \mu \mathrm{M}$ of PHA665752 for 3 days, the axon length of CSMNs was reduced 3.42-fold in the non-TG group and 2.33-fold in the TG group (Fig. 5b). This result indicated that endogenously expressed HGF could positively affect the axonal outgrowth of CSMNs.

When $100 \mathrm{ng} / \mathrm{ml}$ of $\mathrm{rHGF}$ were added to the culture for 3 days, however, the axon length of CSMNs was increased by $48.61 \%$ in the non-TG group, and by $124.73 \%$ in the TG group (Fig. 5c). When PHA665752 was co-treated with rHGF, the HGF-mediated increase of CSMNs' axon length was inhibited by $127.7 \%$ in the non-TG group, and by $120.82 \%$ in the TG group (Fig. $5 d)$. This is consistent with the data in Fig. 7a-b showing activation or inhibition of phosphorylation of the Met protein by HGF or PHA665752. These results suggested that activation of the HGF-Met signaling pathway might be involved in the promotion of axonal outgrowth of CSMNs.

\section{Effects of inhibition of ERK, PI3K, and p38 on axonal outgrowth of CSMNs}

Several signaling pathways have been shown to be turned on upon interaction between HGF and Met receptor. To identify the key pathway involved in the regulation of the HGF-mediated axonal outgrowth of CSMNs, $2 \times 10^{4}$ cells were treated with specific chemical inhibitors for ERK (U0126), PI3K (LY294002), p38 (SB203580), and JNK (SP600125). When cells were treated with 3 different concentrations of respective inhibitors, the axon length of CSMNs was reduced in a dose-dependent manner by all agents except for SP600125 (Fig. 6a-d). In all concentrations of chemical 

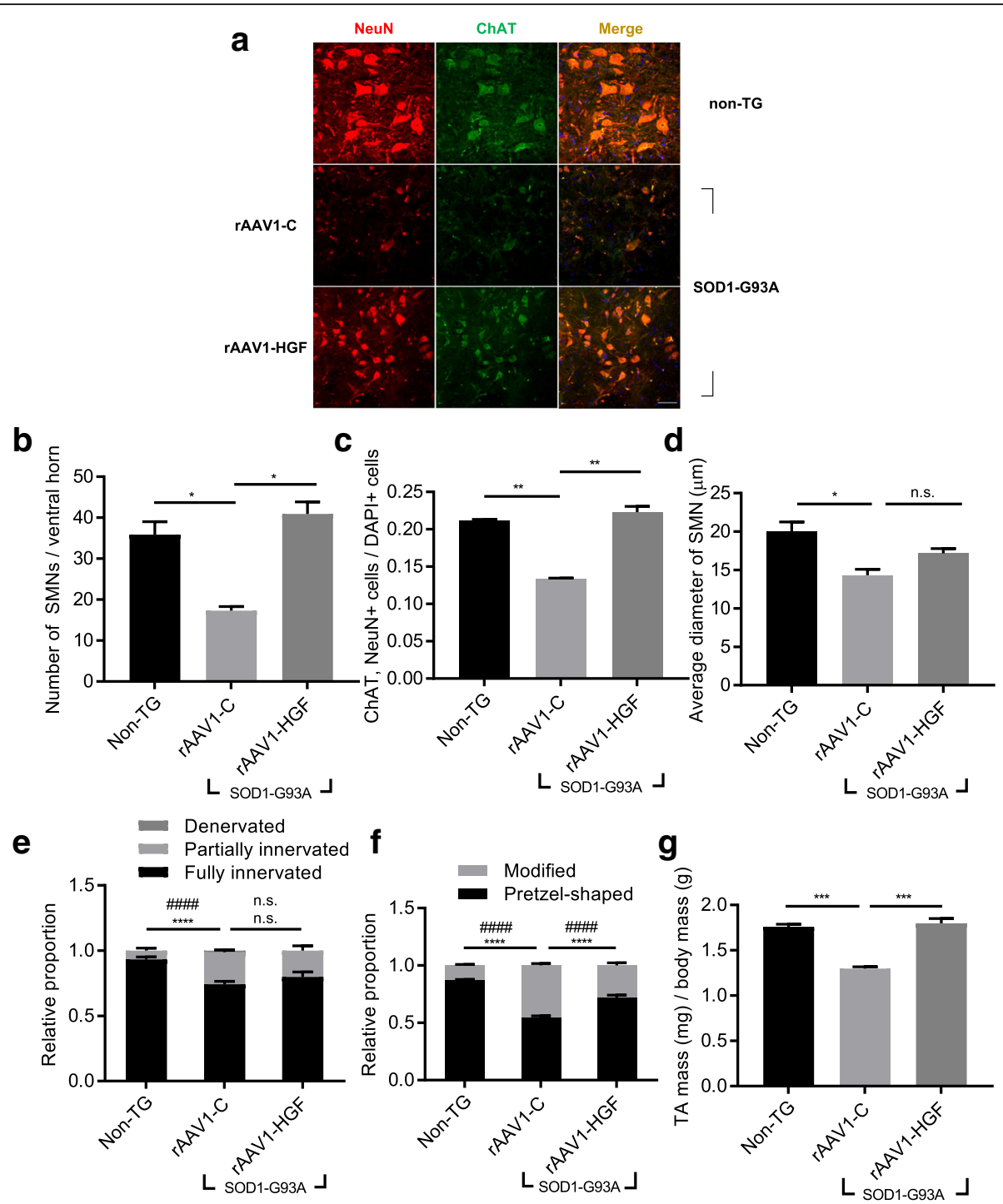

Fig. 4 IT delivery of rAAV1-HGF led to histological improvements of SMNs and NMJs in SOD1-G93A TG mice. a-g non-TG or TG mice at P60 were intrathecally injected with rAAV1-C or rAAV1-HGF. The LSCs (a-d) and TA muscles (e-f) were collected at P100, followed by IHC assay. a Representative image of SMNs. Antibodies specific to ChAT and NeuN were used to label SMNs. b Number of SMNs per ventral horn was counted and represented as a bar graph. c Proportion of SMNs per DAPI-positive cells was counted and represented as a bar graph. $\mathbf{d}$ Diameter of SMNs were measured and represented as a bar graph. In, Fig. 4b-d, one-way ANOVA was performed, followed by Tukey's post-hoc test. e-f The shape and integrity of NMJs were determined as mentioned in Fig. 2 and represented as a bar graph. In Fig. 4e-f, two-way ANOVA was performed, followed by Tukey's post-hoc test. In

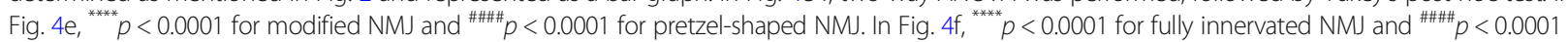
for partially innervated NMJ. $\mathbf{g}$ Relative mass of TA was calculated using total body mass and represented as a bar graph. For bar graphs, values are represented as mean \pm SEM. For statistical analysis, one-way ANOVA was performed, followed by Tukey's post-hoc test. For bar graphs, ${ }^{*} p<0.05,{ }^{* *} p<0.005,{ }^{* * *} p<0.001$, n.s. $>0.05$. Scale bar: $\mathbf{a}=50 \mu \mathrm{m}$

inhibitors used in this experiment, cytotoxic effects were not observed (Additional file 1: Figure S3a). These results suggested that ERK, PI3K, and p38 might play roles in the HGF-mediated axonal outgrowth of CSMNs.

\section{Effects of rHGF on ERK phosphorylation}

We tested whether HGF could activate ERK, PI3K, and p38 in the cortical culture. $3.2 \times 10^{6}$ cells were treated with $100 \mathrm{ng} / \mathrm{ml}$ of rHGF, and 5 days later, total proteins were extracted, followed by Western blot analysis. As shown in Fig. 7a, the level of phosphorylated ERK was increased by treatment with rHGF, while the levels of PI3K and p38 were not affected. The effect of rHGF was inhibited when cells were co-treated with $1 \mu \mathrm{M}$ of PHA665752 or $10 \mu \mathrm{M}$ of U0126 (Fig. 7b-c), suggesting that the HGF-Met pathway is involved in the phosphorylation of ERK in this cortical culture. We tested whether inhibition of ERK could reduce the HGF-mediated increase of the 


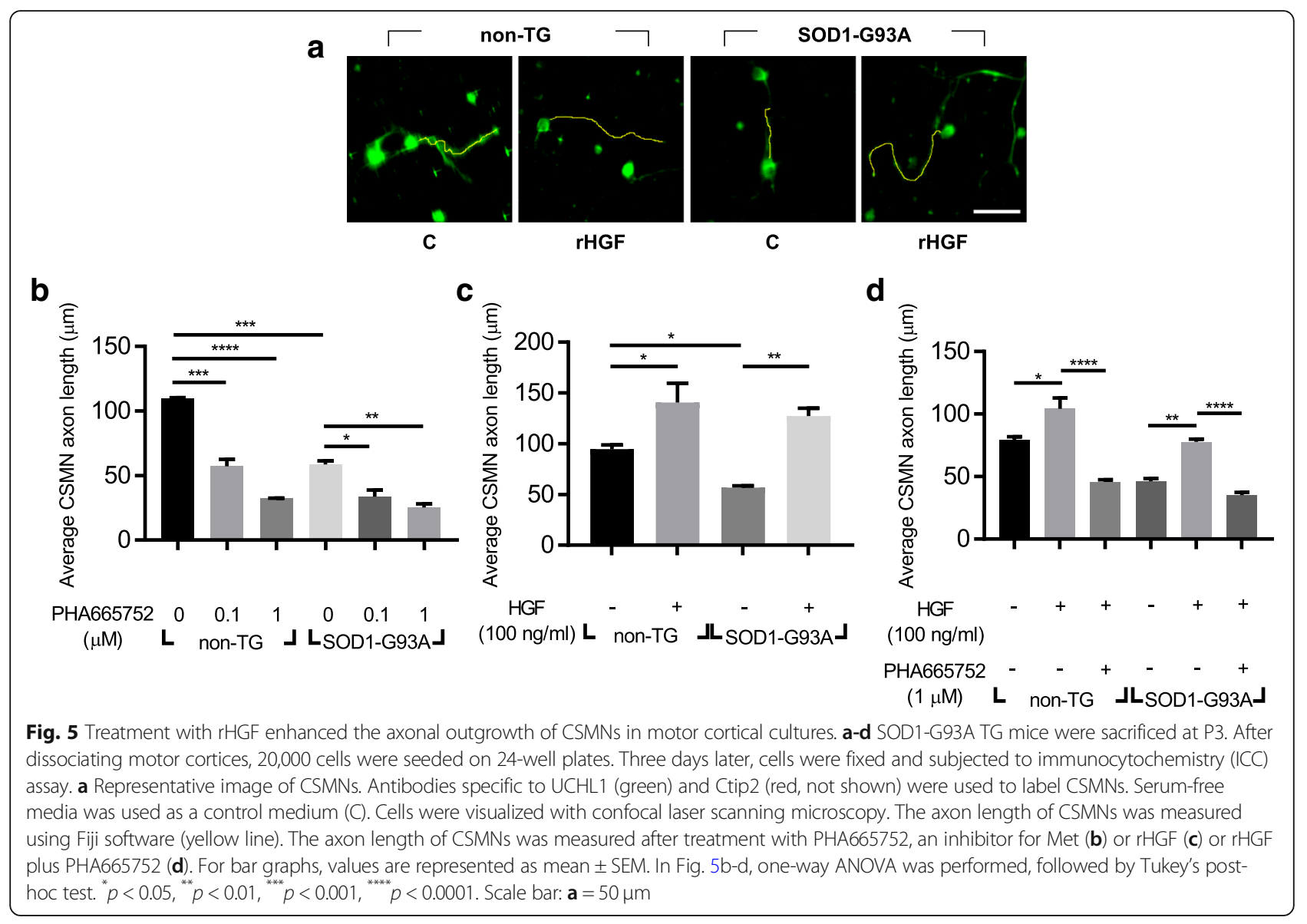

axon length of CSMNs. As shown in Fig. 7d, treatment with U0126 decreased the axon length of CSMNs 2.41-fold in the non-TG group and 2.03-fold in the TG group, indicating that HGF could promote axonal outgrowth of CSMNs by specifically up-regulating phosphorylation of ERK.

To test whether the above in vitro results were reproducible in vivo, $5 \times 10^{9} \mathrm{GC}$ of viral vectors were intrathecally injected into SOD1-G93A TG mice at P60, and the LSC was analyzed for ERK. Compared with non-TG mice, the level of phosphorylated ERK was increased 2.04-fold in TG mice injected with a control vector, and was further enhanced 5.54-fold when injected with AAV vectors expressing HGF (Fig. 7e-f). There was no difference in phosphorylation of other signaling molecules of the HGF-Met pathway, such as STAT3, cJUN, and GSK3 $\beta$ (Additional file 1: Figure S4a). These results indicated that ERK might indeed be an important factor of the HGF-mediated regeneration of motor neurons.

Effects of HGF-mediated ERK phosphorylation on levels of ROS

To get an overall picture of the effects of HGF on gene expression profile in CSMNs, cortical cells were treated with $100 \mathrm{ng} / \mathrm{ml}$ of $\mathrm{rHGF}$, and total RNAs were extracted followed by microarray assay (Additional file 1: Figure S5a). Among the 116 genes whose expression levels were changed more than 1.5-fold, 52 belonged to six major categories defined for fALS by Taylor et al., and 37 (71.15\%) were involved in the control of protein quality and RNA metabolism [49]. Therefore, we tested whether the HGF-Met-ERK signaling pathway could reduce hSOD1 protein aggregation and/or oxidative stress. Cortical cells were treated with rHGF, followed by IHC to examine the distribution of mutant hSOD1. When compared to the non-TG group containing no hSOD1 aggregates, the proportion of CSMNs in the TG group with hSOD1 aggregates was sharply increased to $0.4 \pm 0.01$ as shown in Fig. 8a-b. When treated with rHGF, however, this proportion was reduced to $0.06 \pm 0.02$, while it was increased to $0.3 \pm 0.06$ and $0.33 \pm 0.04$ by the addition of inhibitors for Met (PHA665752) or ERK (U0126), respectively (Fig. 8a).

Since the aggregated form of mutant hSOD1 could increase oxidative stress, it was also tested whether the rHGF-mediated reduction of protein aggregation could alleviate oxidative stress by measuring hydrogen peroxide, peroxynitrite, hydroxyl radicals, nitric oxide, 

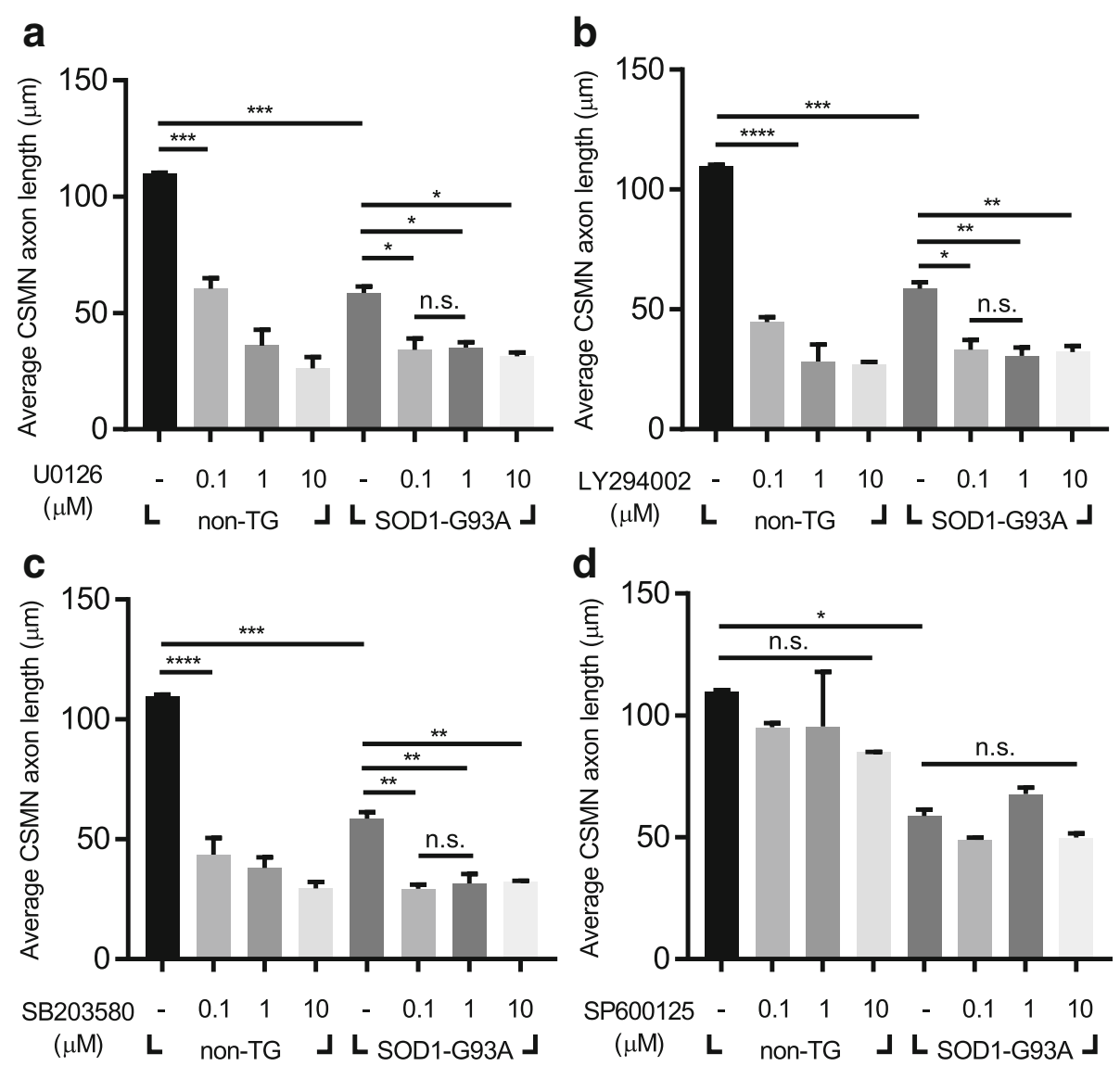

Fig. 6 Inhibition of ERK, PI3K, and P38 resulted in decreased axonal outgrowth of CSMNs. a-d The axon length of CSMNs was measured and represented as a bar graph after treatment with U0126 (ERK inhibitor) (a), LY294002 (PI3K inhibitor) (b), SB203580 (p38 inhibitor) (c), and SP600125 (JNK inhibitor) (d). For bar graphs, values are represented as mean \pm SEM. In Fig. 6a-d, one-way ANOVA was performed, followed by Tukey's posthoc test. ${ }^{*} p<0.05,{ }^{* *} p<0.01,{ }^{* * *} p<0.001,{ }^{* * * *} p<0.0001$, n.s. $>0.05$

and peroxy radical in the cortical culture. Compared to the control group treated with SFM, treatment with rHGF decreased the level of oxidative stress by $34.22 \%$, which was comparable to the effect (32.11\%) of $\mathrm{N}$-acetyl-L-cysteine (NAC), a well-known scavenger of oxygen free radical (Fig. 8c). Such HGF-mediated decrease of oxidative stress was inhibited by 15.51 and $18.81 \%$ when rHGF was co-treated with PHA665752 and U0126, respectively (Fig. 8c).

To test whether the axonal outgrowth of CSMNs could be promoted by alleviation of oxidative stress, the effect of rHGF was tested in the presence of pyocyanin, a ROS inducer. As shown in Fig. 8d, the axon length of CSMNs was increased by $40.12 \%$ when treated with NAC. The effect of rHGF was almost 3-fold greater at $118.83 \%$, which was inhibited by $32.1 \%$ in the presence of pyocyanin. Taken together, these results indicated that HGF-mediated induction of ERK phosphorylation plays an important role(s) in promoting the axonal outgrowth of CSMNs by mitigating protein aggregation and oxidative stress.

\section{Discussion}

In this report, we explored the possibility of delivering the HGF gene by IT injection of rAAV vector for neuromuscular diseases. It was found that AAV serotype 1 could most effectively deliver and express the transgene in the ventral horn. rAAV1-HGF produced the HGF protein in a bell shape kinetics pattern over the course of 16 weeks, with peak level achieved at 2 weeks post-injection. In two neuromuscular disease modelsthe sciatic nerve crush and SOD1-G93A TG mouse models-a single administration of rAAV1-HGF into the LSC improved motor functions and NMJ structure. These results indicated that rAAV1 expressing HGF might have regenerative potential and improve symptomatic motor performance.

Of particular interest was the finding that IT injection of rAAV1-HGF could not only facilitate protection of but also delay the degeneration of motor neurons. In the sciatic nerve crush model, for example, the regenerative process takes place after Wallerian degeneration following nerve injury, and rAAV1-HGF was shown to 


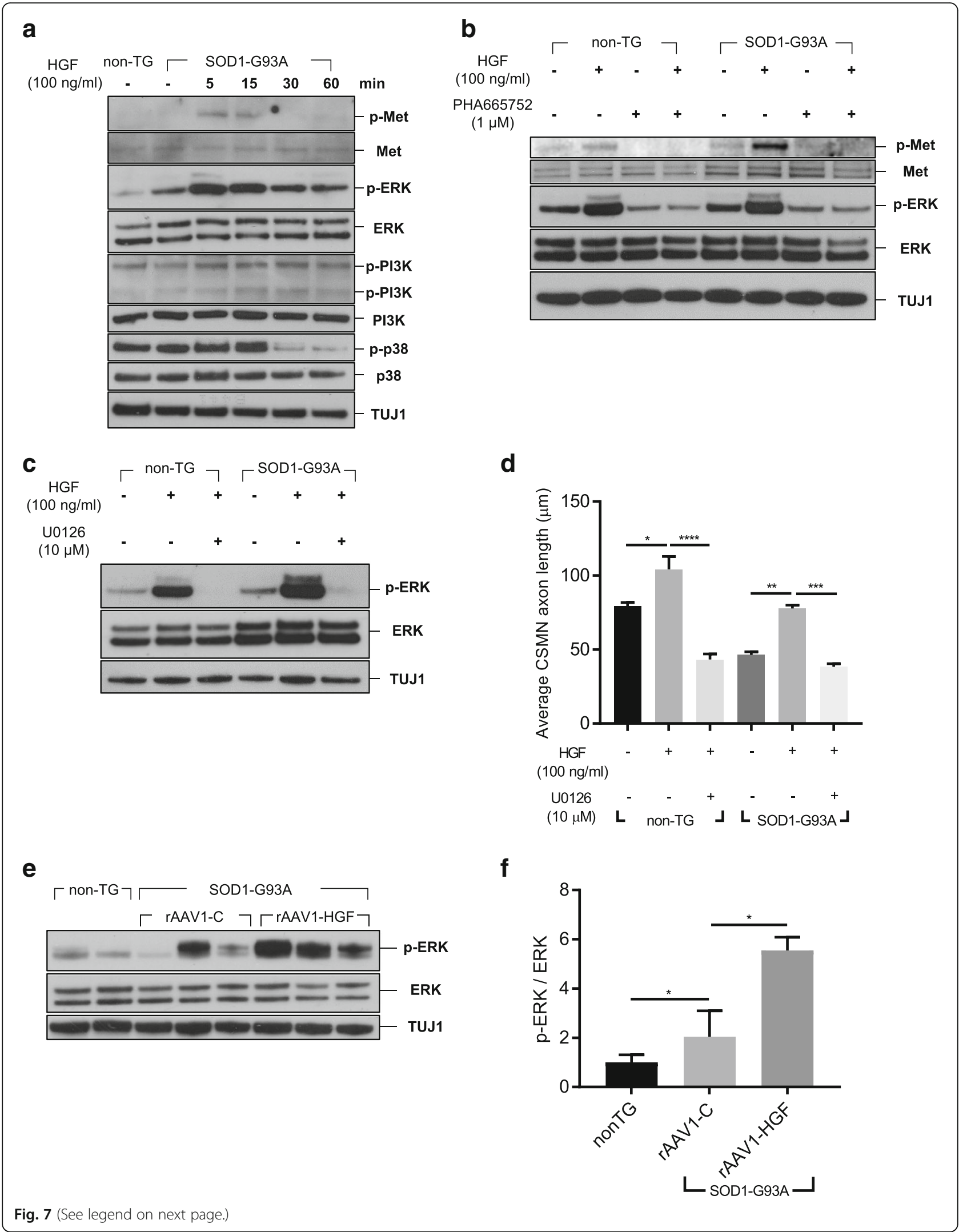


(See figure on previous page.)

Fig. 7 Phosphorylation of ERK was increased by treatment with HGF in the LSC and motor cortical cultures. a-c Motor cortices from non-TG or TG mice at P3 were collected. After dissociation, cells were seeded on six-well plates with $3.2 \times 10^{6}$ cells/well. a Cells were treated with $100 \mathrm{ng} / \mathrm{ml}$ of rHGF, and 5 days later, total proteins were isolated, followed by Western blot analysis. b-c Cells were treated with $1 \mu \mathrm{M}$ of PHA665752 or $10 \mu \mathrm{M}$ of U0126. After $30 \mathrm{~min}$, cells were treated with $100 \mathrm{ng} / \mathrm{ml}$ of rHGF, and five days later, total proteins were isolated followed by Western blot analysis. DMSO was used as a negative control. $\mathbf{d}$ The axon length of CSMNs was measured and represented as a bar graph after co-treatment with rHGF and U0126. For statistical analysis, one-way ANOVA was performed, followed by Tukey's post-hoc test. e-f non-TG or TG mice at P60 were intrathecally injected with rAAV1-C or rAAV1-HGF. The LSCs were collected, and total proteins were extracted at P100, followed by Western blot analysis (e). Relative levels of phosphorylated ERK were measured using Fiji software and represented as a bar graph (f). For bar graphs, values are represented as mean \pm SEM. For statistical analysis, one-way ANOVA was performed, followed by Tukey's post-hoc test. ${ }^{*} p<0.05$, ${ }^{* * *} p<0.01,{ }^{* * *} p<0.001,{ }^{* * * *} p<0.0001$

promote the regeneration of the sciatic nerves and the recovery of NMJ structure. On the other hand, in the SOD1-G93A TG mouse model, progressive degeneration of motor neurons and muscles occurs, and rAAV1-HGF could delay disease progression and degeneration of SMNs. Therefore, rAAV1-HGF appears to provide dual activities in the pathogenesis of motor neuron degeneration that may result in additive effects.

Our results are consistent with previous studies showing the potentially positive roles of HGF or Met in ALS patients or related animal models. Protein levels of HGF and Met increase in the ventral horn of sALS patients at the early stage, while patients with motor neurons defective in HGF or Met are more susceptible to disease progression of ALS, being atrophied rapidly [20]. In SOD1-G93A TG mice, RNA levels of HGF and Met were higher than the non-TG control, presumably to respond to or compensate for pathological conditions [48]. In the same model, disease progression was shown to be delayed and the survival rate to be increased when either HGF or Met were overexpressed specifically in motor neurons or when rHGF was injected into the spinal cord. Together with our results, HGF appears to be a strong candidate that may be used for developing therapeutics for ALS.

Although protein levels of HGF and Met have been shown to increase in SOD1-G93A TG mice, the level of biologically active forms of these proteins has not been well studied in the LSC at the symptomatic stage. We found that the level of phosphorylated Met was slightly lower in SMNs of the ventral horn of SOD1-G93A TG mice at P100, indicating that the level of endogenously expressed HGF might not be sufficient to fully activate Met. When TG mice were intrathecally injected with rAAV1-HGF, however, the fraction of SMNs expressing phosphorylated Met approximately doubled, suggesting that exogenously added HGF could augment the activation of Met. Therefore, HGF appeared to produce cell-autonomous effects by directly affecting SMNs. HGF is also expected to generate non-autonomous effects by acting on glial cells such as astrocytes and microglia. We previously showed that HGF produced from plasmid DNA expression vector could lower the level of ATF3 and CSF1 in DRG and change the distribution of activated microglia in the dorsal horn in the mouse chronic constriction injury model [33]. Others also reported that treatment of primary astrocytes with HGF in vitro reduced the protein level of EAAT2, a glutamate transporter, and enhance the expression level of total Met in reactive astrocytes in the spinal cord [20, 48]. We also observed that treatment with rHGF could lower the levels of LPS-induced TNFa in the primary astrocyte culture system (data not shown). Together with the cell-autonomous effects described above, HGF has, when properly delivered to patients, the potential to generate powerful therapeutic effects by controlling two of the most important pathways in the pathogenesis of ALS and related motor neuron diseases.

Improvements in motor functions, NMJ morphology, and the protection of SMNs observed in this study could have resulted from 3 sources: changes in SMNs, in upper motor neurons, or in a combination of both neurons. HGF is known as a potent neurotrophic factor, which can facilitate the proliferation, migration, differentiation, and survival of sensory neurons, as well as motor neurons $[19,26,27,34]$. The interaction of HGF with lower motor neurons has been relatively well characterized. For example, it has been reported that HGF could function as a survival factor for SMNs in vitro $[8,54$, 56]. In addition, HGF has also been shown to induce remyelination of Schwann cells to promote axonal outgrowth of peripheral neurons [24]. These findings suggested that HGF could directly and/or indirectly protect damaged lower motor neurons.

On the other hand, the molecular mechanisms of HGF's interaction with upper motor neurons have been poorly understood up until now. In this study, therefore, we investigated the effects of HGF on upper motor neurons in vitro, using the primary motor cortical culture system consisting of CSMNs and glial cells. It was observed that HGF could facilitate the axonal outgrowth of CSMNs by controlling the phosphorylation of ERK. When phenotypes of oxidative stress were analyzed based on microarray data, treatment of CSMNs with HGF protein was found to reduce the accumulation of mutant SOD1 proteins and levels of oxidative stress 


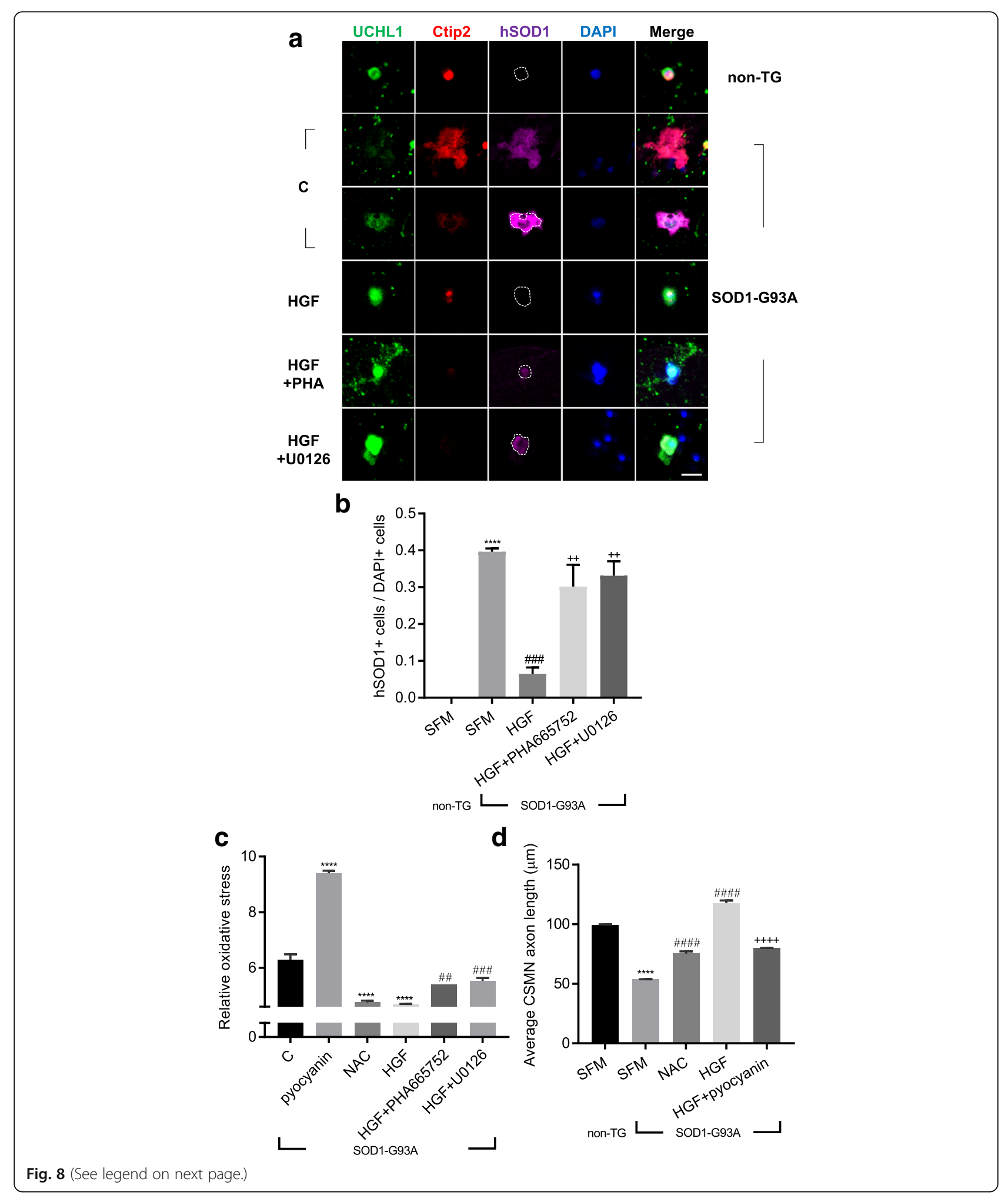


(See figure on previous page.)

Fig. 8 Treatment with rHGF reduced levels of protein aggregation and oxidative stress induced by mutant SOD1. a-b ICC assay was performed as described in Fig. 5a. Antibodies specific to UCHL1 and Ctip2 were used to label CSMNs, together with those for hSOD1 (magenta). C: Treated with SFM. In the hSOD1-stained panels, the cell boundaries of the CSMNs were outlined based on the UCHL1 signals, except for the panel in the second row, where the cell boundaries are ambiguous. Proportion of hSOD1-positive cells per DAPI-positive cells was counted and represented as a bar graph (b). For statistical analysis, one-way ANOVA was performed, followed by Tukey's post hoc test. ${ }^{* * * *} p<0.0001$ for non-TG SFM vs. TG SFM, ${ }^{\# \# \#} \mathrm{p}<0.001$ for TG SFM vs. TG HGF, ${ }^{++} p<0.01$ for TG HGF vs. TG HGF + PHA665752 (or TG HGF + U0126). c $6.4 \times 10^{4}$ cells were seeded on 96-well plates. Cellular ROS levels were measured using a ROS detection kit and represented as a bar graph. Pyocyanin was used as an inducer of ROS, whereas N-acetyl-L-cysteine (NAC) was employed as a scavenger of ROS. For statistical analysis, one-way ANOVA was performed, followed by Tukey's post-hoc test. ${ }^{* * * *} p<0.0001$ for SFM vs. pyocyanin (or NAC or HGF), ${ }^{\# \#} p<0.01$ for HGF vs. HGF + PHA665752, ${ }^{\# \# \#} p<0.001$ for HGF vs. HGF + U0126. $\mathbf{d}$ The axon length of CSMNs was measured and represented as a bar graph. For bar graphs, values are represented as mean \pm SEM. For statistical analysis, one-way ANOVA was performed, followed by Tukey's post-hoc test. ${ }^{* * * * *} p<0.0001$ for non-TG SFM vs. TG SFM, \#\#\# $\mathrm{p}<0.0001$ for TG SFM vs. TG NAC (or TG HGF), ${ }^{++++} p<0.0001$ for TG HGF vs. TG HGF + pyocyanin. Scale bar: $\mathbf{a}=20 \mu \mathrm{m}$

factors such as $\mathrm{H}_{2} \mathrm{O}_{2}, \mathrm{ONOO}^{-}$, $\mathrm{HO}$, NO, and ROO. All these effects were inhibited, however, when ERK phosphorylation was suppressed by U0126. These results suggested that upper motor neurons could also have played a role in the effects exerted by rAAV1-HGF, and that ERK might be a key signaling factor involved.

It is also possible that HGF expressed from rAAV1-HGF could have affected both spinal and upper motor neurons, so observed improvements in the SOD1-G93A TG mouse model might have come from the combined effects. Our preliminary data indicated that intramuscular injection of rAAV6-HGF into the tibialis anterior did not have particularly visible effects on motor functions and other parameters (data not shown). Therefore, we are inclined to think that the role of upper motor neurons may have been more important in this particular model.

In summary, our data suggested that exogenously added HGF, in the form of rAAV1-HGF intrathecally delivered to the LSC area, could improve behavioral defects and survival rates in SOD1-G93A TG mice. ERK activated by HGF from rAAV1-HGF appeared to play a key role(s) in HGF-mediated effects such as alleviation of oxidative stress and facilitation of protection, and delay of degeneration of motor neurons. Taken together, it appears that rAAV1-HGF may be developed as a novel therapeutic agent for various diseases in which motor neuron degeneration is the major pathologic cause.

\section{Additional file}

Additional file 1: Figure S1. Production of HGF-expressing rAAV vector. a To co-express two isoforms of HGF, HGF723 (or dHGF) and HGF728 (or CHGF), a gDNA-cDNA-hybrid sequence was generated. In this chimeric sequence, a part of intron 4 of the HGF gene was inserted between cDNA sequences of exon 4 and exon 5, allowing alternative splicing. Since the length of intron 4 is relatively long, sequences between 246 and 4486 were deleted $(\Delta)$. The numbers represented indicate relative positions of intron 4 , and ' 1 ' corresponds to the first nucleotide of intron 4. b $1.6 \times 10^{5} \mathrm{C} 2 \mathrm{C} 12$ cells were transduced with $1.23 \times 10^{8} \mathrm{GC}$ of rAAV2, and 48 hours later, total RNAs were isolated followed by RT-PCR and acrylamide gel analysis. rAAV2-C lacking the HGF sequence was used as a negative control (NC). The upper arrow indicates the amplicon size of
CHGF (142 bp), while the lower arrow shows the amplicon size of dHGF (127 bp). c $8 \times 10^{4}$ C2C12 cells were transduced with $5 \times 10^{13} \mathrm{GC}$ of rAAV2, and 48 hours later, supernatant was collected followed by ELISA for hHGF. rAAV2-C lacking the HGF sequence was used as a negative control. $\mathrm{ND}$ indicates that values were not detectable or lower than the minimum detectable dose. $\mathbf{d}$ C57BL/6 mice at P60 were intrathecally injected with $5 \times 10^{9}$ GC of rAAV1-C or rAAV1-HGF. The LSCs, motor cortices, serum, and TA were collected 8 weeks after injection and subjected to ELISA for hHGF. For bar graphs, values are represented as mean \pm SEM. Figure S2. Levels of phosphorylated Met after IT delivery of rAAV1-HGF. a non-TG or TG mice at P60 were intrathecally injected with $5 \times 10^{9} \mathrm{GC}$ of rAAV1-C or rAAV1-HGF. The LSCs were collected at P100. Tissues were fixed and subjected to IHC assay. Antibodies specific to ChAT (green) and NeuN (red) were used to label SMNs, together with those for p-Met (magenta). b The proportion of SMNs expressing p-MET per total SMNs was measured and represented as a bar graph. For bar graphs, values are represented as mean \pm SEM. Scale bar: $\mathbf{a}=20 \mu \mathrm{m} .{ }^{*} p<0.05$, n.s. $>0.05$. Figure S3. Effects of rHGF or chemical inhibitors measured by WST1 assay in motor cortical cells. a After dissociating motor cortices of P3 non-TG or TG mice, $1.6 \times 10^{5}$ cells were seeded on PDL-coated 48-well cell plates in the presence of rHGF or respective inhibitors. Three days later, WST1 assay was performed. Cell viability was measured using a microplate reader and represented as a bar graph. For the bar graph, values are represented as mean \pm SEM. n.s. $>0.05$. Figure S4. Western blot analysis in the LSC after IT delivery of rAAV1-HGF. a non-TG or TG mice at P60 were intrathecally injected with $5 \times 10^{9} \mathrm{GC}$ of rAAV1-C or rAAV1-HGF. The LSCS were collected at P100. Total proteins were extracted and subjected to Western blot analysis. Figure S5. Microarray analysis of motor cortical cells treated with rHGF. a Motor cortical cells were treated with 100 ng/ $\mathrm{ml}$ of $\mathrm{rHGF}$ for 3 days, followed by microarray analysis using Affymetrix Genechip. SFM was used as a negative control (NC). After data extraction, RMA normalization was performed followed by DEG analysis. Differential expression was represented by color gradients. Genes were clustered based on 6 major categories defined by Taylor et al., as described in Results. Genes involved in protein quality control are labeled in red, while those related to RNA metabolism are labeled in blue. The rest of genes are labeled in black. The NC group is for non-TG NC vs. TG NC, whereas the rHGF group is for TG NC vs. TG rHGF. Table S1. Antibodies and primers used in this study. $\mathbf{a}-\mathbf{b}$ List of antibodies used for Western blot analysis (a) and immunostaining (b). c List of primers used for murine IL2 and human SOD1 to determine the copy number of mhSOD1. F: Forward primer, R: Reverse primer. (PPTX $7050 \mathrm{~kb}$ )

\section{Acknowledgements}

We would like to thank Dr. Pembe Hande Özdinler for help with learning in vitro motor cortical culture system and Dr. Y. H. Hong for critically reading the manuscript.

\section{Funding}

This research was supported in part by grant (no. HI16C1222) of the Korea Health Technology R\&D Project through the Korea Health Industry Development Institute (KHIDI) under the Ministry of Health \& Welfare, Republic of Korea. 


\section{Availability of data and materials}

The datasets during and/or analyzed during the current study available from the corresponding author on reasonable request.

\section{Authors' contributions}

SHL designed the experiments, performed the experiments, analyzed the data, and wrote the manuscript. $J L, N L$, and Subin Kim conducted the experiments. SSY designed the study. JHK analyzed data and critically reviewed the manuscript. Sunyoung Kim directed the overall study, including designing the experiments, analyzing the data, and writing the manuscript. All authors read and approved the final manuscript.

\section{Ethics approva}

All experimental procedures in studies involving animals were in accordance with the ethical standards of the Seoul National University Institutional Animal Care and Use Committee (IACUC). This article does not contain any studies with human participants performed by any of the authors.

\section{Consent for publication}

\section{Not applicable.}

\section{Competing interests}

Junghun Lee, Nayeon Lee, Seung Shin Yu, and Sunyoung Kim are employees or shareholders of ViroMed Co., Ltd. The other authors declare that they have no competing interests.

\section{Publisher's Note}

Springer Nature remains neutral with regard to jurisdictional claims in published maps and institutional affiliations.

\section{Author details}

${ }^{1}$ R\&D Center for Innovative Medicines, Helixmith Co., Ltd., Building 203, Gwanak-Gu, Seoul 08826, Korea. ${ }^{2}$ School of Biological Sciences, Seoul National University, Gwanak-Gu, Seoul 08826, Korea.

Received: 30 March 2019 Accepted: 13 May 2019

Published online: 12 June 2019

\section{References}

1. Ajroud-Driss S, Christiansen M, Allen JA, Kessler JA (2013) Phase 1/2 openlabel dose-escalation study of plasmid DNA expressing two isoforms of hepatocyte growth factor in patients with painful diabetic peripheral neuropathy. Mol Ther 21:1279-1286. https://doi.org/10.1038/mt.2013.69

2. Alexander GM, Erwin KL, Byers N, Deitch JS, Augelli BJ, Blankenhorn EP, Heiman-Patterson TD (2004) Effect of transgene copy number on survival in the G93A SOD1 transgenic mouse model of ALS. Mol Brain Res 130:7-15. https://doi.org/10.1016/j.molbrainres.2004.07.002

3. Bensimon G, Lacomblez L, Meininger V (1994) A controlled trial of riluzole in amyotrophic lateral sclerosis. ALS/Riluzole study group. N Engl J Med 330: 585-591. https://doi.org/10.1056/NEJM199403033300901

4. Buning H, Perabo L, Coutelle O, Quadt-Humme S, Hallek M (2008) Recent developments in adeno-associated virus vector technology. J Gene Med 10: 717-733. https://doi.org/10.1002/jgm.1205

5. Cheah BC, Vucic S, Krishnan AV, Kiernan MC (2010) Riluzole, neuroprotection and amyotrophic lateral sclerosis. Curr Med Chem 17:1942-1199

6. Cho KR, Choi JS, Hahn W, Kim DS, Park JS, Lee DS, Kim KB (2008) Therapeutic angiogenesis using naked DNA expressing two isoforms of the hepatocyte growth factor in a porcine acute myocardial infarction model. Eur J Cardiothorac Surg 34:857-863. https://doi.org/10.1016/j.ejcts.2008.05.045

7. Daya S, Berns KI (2008) Gene therapy using adeno-associated virus vectors. Clin Microbiol Rev 21:583-593. https://doi.org/10.1128/Cmr.00008-08

8. Ebens A, Brose K, Leonardo ED, Hanson MG Jr, Bladt F, Birchmeier C, Barres BA, Tessier-Lavigne M (1996) Hepatocyte growth factor/scatter factor is an axonal chemoattractant and a neurotrophic factor for spinal motor neurons. Neuron 17:1157-1172

9. Genc B, Jara JH, Schultz MC, Manuel M, Stanford MJ, Gautam M, Klessner JL, Sekerkova G, Heller DB, Cox GA, Heckman CJ, DiDonato CJ, Ozdinler PH (2016) Absence of UCHL 1 function leads to selective motor neuropathy. Ann Clin Transl Neurol 3:331-345. https://doi.org/10.1002/acn3.298

10. Genestine M, Caricati E, Fico A, Richelme S, Hassani H, Sunyach C, Lamballe F, Panzica GC, Pettmann B, Helmbacher F, Raoul C, Maina F, Dono R (2011)
Enhanced neuronal Met signalling levels in ALS mice delay disease onset. Cell Death Dis 2:e130. https://doi.org/10.1038/cddis.2011.11

11. Gu YQ, Zhang J, Guo LR, Cui SJ, Li XF, Ding DY, Kim JM, Ho SH, Hahn W, Kim S (2011) A phase I clinical study of naked DNA expressing two isoforms of hepatocyte growth factor to treat patients with critical limb ischemia. J Gene Med 13:602-610. https://doi.org/10.1002/jgm.1614

12. Gurney ME (1995) Motor-Neuron Degeneration in Mice That Express a Human Cu,Zn Superoxide-Dismutase Mutation (Vol 264, Pg 1772, 1994). Science 269:149-149. https://doi.org/10.1126/science.269.5221.149-a

13. Hardiman O, van den Berg LH, Kiernan MC (2011) Clinical diagnosis and management of amyotrophic lateral sclerosis. Nat Rev Neurol 7:639-649. https://doi.org/10.1038/nrneurol.2011.153

14. Henry TD, Hirsch AT, Goldman J, Wang YL, Lips DL, McMillan WD, Duval S, Biggs TA, Keo HH (2011) Safety of a non-viral plasmid-encoding dual isoforms of hepatocyte growth factor in critical limb ischemia patients: a phase I study. Gene Ther 18:788-794. https://doi.org/10.1038/gt.2011.21

15. Inloes JM, Hsu KL, Dix MM, Viader A, Masuda K, Takei T, Wood MR, Cravatt BF (2014) The hereditary spastic paraplegia-related enzyme DDHD2 is a principal brain triglyceride lipase. Proc Natl Acad Sci U S A 111:1492414929. https://doi.org/10.1073/pnas.1413706111

16. Ishigaki A, Aoki M, Nagai M, Warita H, Kato S, Kato M, Nakamura T, Funakoshi H, Itoyama Y (2007) Intrathecal delivery of hepatocyte growth factor from amyotrophic lateral sclerosis onset suppresses disease progression in rat amyotrophic lateral sclerosis model. J Neuropathol Exp Neurol 66:1037-1044. https://doi.org/10.1097/nen.0b013e318159886b

17. Ishiki Y, Ohnishi H, Muto Y, Matsumoto K, Nakamura T (1992) Direct evidence that hepatocyte growth-factor is a hepatotrophic factor for liverregeneration and has a potent antihepatitis effect invivo. Hepatology 16: 1227-1235. https://doi.org/10.1016/0270-9139(92)90019-6

18. Jara JH, Genc B, Cox GA, Bohn MC, Roos RP, Macklis JD, Ulupinar E, Ozdinler $\mathrm{PH}$ (2015) Corticospinal motor neurons are susceptible to increased ER stress and display profound degeneration in the absence of UCHL1 function. Cereb Cortex 25:4259-4272. https://doi.org/10.1093/cercor/bhu318

19. Kadoyama K, Funakoshi H, Ohya W, Nakamura T (2007) Hepatocyte growth factor (HGF) attenuates gliosis and motoneuronal degeneration in the brainstem motor nuclei of a transgenic mouse model of ALS. Neurosci Res 59:446-456. https://doi.org/10.1016/j.neures.2007.08.017

20. Kato S, Funakoshi H, Nakamura T, Kato M, Nakano I, Hirano A, Ohama E (2003) Expression of hepatocyte growth factor and c-Met in the anterior horn cells of the spinal cord in the patients with amyotrophic lateral sclerosis (ALS): immunohistochemical studies on sporadic ALS and familial ALS with superoxide dismutase 1 gene mutation. Acta Neuropathol 106: 112-120. https://doi.org/10.1007/s00401-003-0708-z

21. Kessler JA, Smith AG, Cha BS, Choi SH, Wymer J, Shaibani A, Ajroud-Driss S, Vinik A, Group VD-IS (2015) Double-blind, placebo-controlled study of HGF gene therapy in diabetic neuropathy. Ann Clin Transl Neurol 2:465-478. https://doi.org/10.1002/acn3.186

22. Kibbe MR, Hirsch AT, Mendelsohn FO, Davies MG, Pham H, Saucedo J, Marston W, Pyun WB, Min SK, Peterson BG, Comerota A, Choi D, Ballard J, Bartow RA, Losordo DW, Sherman W, Driver V, Perin EC (2016) Safety and efficacy of plasmid DNA expressing two isoforms of hepatocyte growth factor in patients with critical limb ischemia. Gene Ther 23:399. https://doi.org/10.1038/gt.2016.9

23. Kiernan MC, Vucic S, Cheah BC, Turner MR, Eisen A, Hardiman O, Burrell JR, Zoing MC (2011) Amyotrophic lateral sclerosis. Lancet 377:942-955. https:// doi.org/10.1016/S0140-6736(10)61156-7

24. Ko KR, Lee J, Lee D, Nho B, Kim S (2018) Hepatocyte growth factor (HGF) promotes peripheral nerve regeneration by activating repair Schwann cells. Sci Rep 8:8316. https://doi.org/10.1038/s41598-018-26704-x

25. Kumar R, Hunt CR, Gupta A, Nannepaga S, Pandita RK, Shay JW, Bachoo R, Ludwig T, Burns DK, Pandita TK (2011) Purkinje cell-specific males absent on the first (mMof) gene deletion results in an ataxiatelangiectasia-like neurological phenotype and backward walking in mice. Proc Natl Acad Sci U S A 108:3636-3641. https://doi.org/10.1073/ pnas.1016524108

26. Maina F, Hilton MC, Ponzetto C, Davies AM, Klein R (1997) Met receptor signaling is required for sensory nerve development and HGF promotes axonal growth and survival of sensory neurons. Genes Dev 11:3341-3350. https://doi.org/10.1101/gad.11.24.3341

27. Maina F, Klein R (1999) Hepatocyte growth factor, a versatile signal for developing neurons. Nat Neurosci 2:213-217. https://doi.org/10.1038/6310 
28. Matsuda Y, Matsumoto K, Ichida T, Nakamura T (1995) Hepatocyte growth factor suppresses the onset of liver cirrhosis and abrogates lethal hepatic dysfunction in rats. J Biochem 118:643-649

29. McEown K, Takata Y, Cherasse Y, Nagata N, Aritake K, Lazarus M (2016) Chemogenetic inhibition of the medial prefrontal cortex reverses the effects of REM sleep loss on sucrose consumption. Elife 5. https://doi.org/10.7554/ elife.20269

30. Miyazawa T, Matsumoto K, Ohmichi H, Katoh H, Yamashima T, Nakamura T (1998) Protection of hippocampal neurons from ischemia-induced delayed neuronal death by hepatocyte growth factor: A novel neurotrophic factor. J Cerebr Blood F Met 18:345-348. https://doi.org/10.1097/00004647199804000-00001

31. Montesano R, Matsumoto K, Nakamura T, Orci L (1991) Identification of a fibroblast-derived epithelial morphogen as hepatocyte growth-factor. Cell 67:901-908. https://doi.org/10.1016/0092-8674(91)90363-4

32. Nakamura T, Nawa K, Ichihara A (1984) Partial purification and characterization of hepatocyte growth factor from serum of hepatectomized rats. Biochem Biophys Res Commun 122:1450-1459

33. Nho B, Lee J, Lee J, Ko KR, Lee SJ, Kim S (2018) Effective control of neuropathic pain by transient expression of hepatocyte growth factor in a mouse chronic constriction injury model. FASEB J 32:5119-5131. https://doi. org/10.1096/fj.201800476R

34. Okura Y, Arimoto H, Tanuma N, Matsumoto K, Nakamura T, Yamashima T, Miyazawa T, Matsumoto Y (1999) Analysis of neurotrophic effects of hepatocyte growth factor in the adult hypoglossal nerve axotomy model. Eur J Neurosci 11:4139-4144

35. Ozdinler PH, Macklis JD (2006) IGF-I specifically enhances axon outgrowth of corticospinal motor neurons. Nat Neurosci 9:1371-1381. https://doi.org/10. 1038/nn1789

36. Paumelle R, Tulasne D, Kherrouche Z, Plaza S, Leroy C, Reveneau S, Vandenbunder B, Fafeur V (2002) Hepatocyte growth factor/scatter factor activates the ETS1 transcription factor by a RAS-RAF-MEK-ERK signaling pathway. Oncogene 21:2309-2319. https://doi.org/10.1038/sj.onc.1205297

37. Ponzetto C, Bardelli A, Zhen Z, Maina F, dalla Zonca P, Giordano S, Grazian A, Panayotou G, Comoglio PM (1994) A multifunctional docking site mediates signaling and transformation by the hepatocyte growth factor/ scatter factor receptor family. Cell 77:261-271

38. Pyun WB, Hahn W, Kim DS, Yoo WS, Lee SD, Won JH, Rho BS, Park ZY, Kim JM, Kim S (2010) Naked DNA expressing two isoforms of hepatocyte growth factor induces collateral artery augmentation in a rabbit model of limb ischemia. Gene Ther 17:1442-1452. https://doi.org/10.1038/gt.2010.101

39. Rothstein JD (2017) Edaravone: A new drug approved for ALS. Cell 171:725. https://doi.org/10.1016/j.cell.2017.10.011

40. Sakakura Y, Kaibori M, Oda M, Okumura T, Kwon AH, Kamiyama Y (2000) Recombinant human hepatocyte growth factor protects the liver against hepatic ischemia and reperfusion injury in rats. J Surg Res 92:261-266. https://doi.org/10.1006/jsre.2000.5913

41. Shang J, Deguchi K, Ohta Y, Liu N, Zhang X, Tian F, Yamashita T, Ikeda Y, Matsuura T, Funakoshi H, Nakamura T, Abe K (2011) Strong neurogenesis, angiogenesis, synaptogenesis, and antifibrosis of hepatocyte growth factor in rats brain after transient middle cerebral artery occlusion. J Neurosci Res 89:86-95. https://doi.org/10.1002/jnr.22524

42. Shin JE, Cho YC, Beirowski B, Milbrandt J, Cavalli V, DiAntonio A (2012) Dual leucine zipper kinase is required for retrograde injury signaling and axonal regeneration. Neuron 74:1015-1022. https://doi.org/10.1016/j.neuron.2012. 04.028

43. Shin JE, Geisler S, DiAntonio A (2014) Dynamic regulation of SCG10 in regenerating axons after injury. Exp Neurol 252:1-11. https://doi.org/10. 1016/j.expneurol.2013.11.007

44. Shiotsuki H, Yoshimi K, Shimo Y, Funayama M, Takamatsu Y, Ikeda K, Takahashi R, Kitazawa S, Hattori N (2010) A rotarod test for evaluation of motor skill learning. J Neurosci Methods 189:180-185. https://doi.org/10. 1016/j.jneumeth.2010.03.026

45. Streit A, Sockanathan S, Perez L, Rex M, Scotting PJ, Sharpe PT, Lovell-Badge $R$, Stern CD (1997) Preventing the loss of competence for neural induction: HGF/SF, L5 and Sox-2. Development 124:1191-1202

46. Streit A, Stern CD, Thery C, Ireland GW, Aparicio S, Sharpe MJ, Gherardi E (1995) A role for HGF/SF in neural induction and its expression in Hensen's node during gastrulation. Development 121:813-824

47. Sufit RL, Ajroud-Driss S, Casey P, Kessler JA (2017) Open label study to assess the safety of VM202 in subjects with amyotrophic lateral sclerosis.
Amyotroph Lat Scl Fr 18:269-278. https://doi.org/10.1080/21678421.2016. 1259334

48. Sun W, Funakoshi H, Nakamura T (2002) Overexpression of HGF retards disease progression and prolongs life span in a transgenic mouse model of ALS. J Neurosci 22:6537-6548 doi:20026634

49. Taylor JP, Brown RH Jr, Cleveland DW (2016) Decoding ALS: from genes to mechanism. Nature 539:197-206. https://doi.org/10.1038/nature20413

50. Trusolino L, Bertotti A, Comoglio PM (2010) MET signalling: principles and functions in development, organ regeneration and cancer. Nat Rev Mol Cell Biol 11:834-848. https://doi.org/10.1038/nrm3012

51. Tu PH, Raju P, Robinson KA, Gurney ME, Trojanowski JQ, Lee VM (1996) Transgenic mice carrying a human mutant superoxide dismutase transgene develop neuronal cytoskeletal pathology resembling human amyotrophic lateral sclerosis lesions. Proc Natl Acad Sci U S A 93:3155-3160

52. Van Belle E, Witzenbichler B, Chen D, Silver M, Chang L, Schwall R, Isner JM (1998) Potentiated angiogenic effect of scatter factor/hepatocyte growth factor via induction of vascular endothelial growth factor: the case for paracrine amplification of angiogenesis. Circulation 97:381-390

53. Williams AH, Valdez G, Moresi V, Qi X, McAnally J, Elliott JL, Bassel-Duby R, Sanes JR, Olson EN (2009) MicroRNA-206 delays ALS progression and promotes regeneration of neuromuscular synapses in mice. Science 326 : 1549-1554. https://doi.org/10.1126/science.1181046

54. Wong V, Glass DJ, Arriaga R, Yancopoulos GD, Lindsay RM, Conn G (1997) Hepatocyte growth factor promotes motor neuron survival and synergizes with ciliary neurotrophic factor. J Biol Chem 272:5187-5191

55. Wooley CM, Sher RB, Kale A, Frankel WN, Cox GA, Seburn KL (2005) Gait analysis detects early changes in transgenic SOD1(G93A) mice. Muscle Nerve 32:43-50. https://doi.org/10.1002/mus.20228

56. Yamamoto Y, Livet J, Pollock RA, Garces A, Arce V, deLapeyriere O, Henderson CE (1997) Hepatocyte growth factor (HGF/SF) is a musclederived survival factor for a subpopulation of embryonic motoneurons. Development 124:2903-2913

57. Yamaura K, Ito K, Tsukioka K, Wada Y, Makiuchi A, Sakaguchi M, Akashima T, Fujimori M, Sawa Y, Morishita R, Matsumoto K, Nakamura T, Suzuki J, Amano J, Isobe M (2004) Suppression of acute and chronic rejection by hepatocyte growth factor in a murine model of cardiac transplantation: induction of tolerance and prevention of cardiac allograft vasculopathy. Circulation 110: 1650-1657. https://doi.org/10.1161/01.CIR.0000143052.45956.71

58. Yasvoina MV, Genc B, Jara JH, Sheets PL, Quinlan KA, Milosevic A, Shepherd GM, Heckman CJ, Ozdinler PH (2013) eGFP expression under UCHL1 promoter genetically labels corticospinal motor neurons and a subpopulation of degeneration-resistant spinal motor neurons in an ALS mouse model. J Neurosci 33:7890-7904. https://doi.org/10.1523/JNEUROSCI. 2787-12.2013

59. Zincarelli C, Soltys S, Rengo G, Rabinowitz JE (2008) Analysis of AAV serotypes 1-9 mediated gene expression and tropism in mice after systemic injection. Mol Ther 16:1073-1080. https://doi.org/10.1038/mt.2008.76

Ready to submit your research? Choose BMC and benefit from:

- fast, convenient online submission

- thorough peer review by experienced researchers in your field

- rapid publication on acceptance

- support for research data, including large and complex data types

- gold Open Access which fosters wider collaboration and increased citations

- maximum visibility for your research: over $100 \mathrm{M}$ website views per year

At $\mathrm{BMC}$, research is always in progress.

Learn more biomedcentral.com/submission 